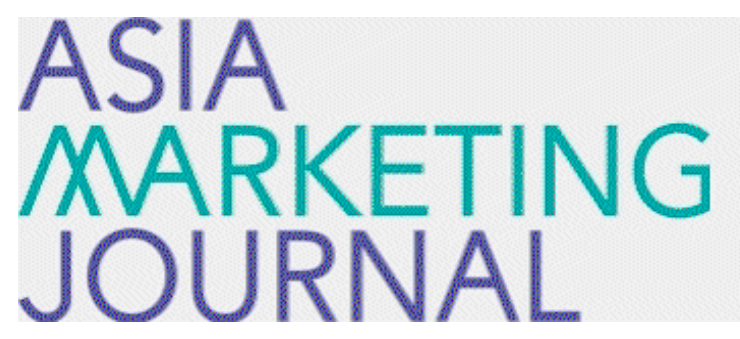

ASIA MARKETING JOURNAL

Volume 9 | Issue 3

Article 4

10-30-2007

\title{
개인 커뮤니티 몰입에 대한 자아표현 및 동일시의 역할
}

Nak Hwan Choi

Chang Won Lee

Follow this and additional works at: https://amj.kma.re.kr/journal

Part of the Marketing Commons

\section{Recommended Citation}

Choi, Nak Hwan and Lee, Chang Won (2007) "개인 커뮤니티 몰입에 대한 자아표현 및 동일시의 역할," Asia Marketing Journal: Vol. 9 : Iss. 3 , Article 4.

Available at: https://doi.org/10.53728/2765-6500.1200

This Article is brought to you for free and open access by Asia Marketing Journal. It has been accepted for inclusion in Asia Marketing Journal by an authorized editor of Asia Marketing Journal. 


\title{
개인 커뮤니티 몰입에 대한 자아표현 및 동일시의 역할
}

\author{
The Roles of Self-Expression and Identification \\ on the Personal Community Commitment
}

\author{
최 낙 환(Choi, Nak Hwan)* \\ 이 창 원(Lee, Chang Won) ${ }^{* *}$
}

기업의 충성도 높은 고객 유치 및 기업 몰입을 위한 하나의 방안으로 대두되고 있는 온라인 개인 커뮤니티의 경우 개인이 미니홈피를 창조하여, 자신을 표현하고 관리하여 커뮤니티를 구축하고, 커뮤 니티와 상호작용하면서 자신을 표현하기 때문에 온라인 개인 커뮤니티와 자아간의 연결인 동일시에 대한 연구가 중요함에도 불구하고 아직까지 이에 대한 연구가 이루어지지 않고 있다. 따라서 본 연구 에서는 온라인 개인 커뮤니터 몰입에 대한 동일시의 역할과 동일시에 영향을 미치는 자아표현의 효 과를 살펴보는데 연구 목적이 있다.

개인 미니홈피를 싸이월드에서 이용하는 소비자들을 대상으로 검증한 결과 첫째. 개인적 실제자아 표현과 개인적 이상자아 표현은 개인적 동일시에 영향을 미치고, 사회적 실제자아 표현과 사회적 이 상자아 표현은 사회적 동일시에 영향을 미치는 것을 알 수 있었다. 둘째, 개인적 동일시와 사회적 동 일시는 모두 온라인 개인 커뮤니티 몰입에 긍정적인 영향을 미치는 것을 알 수 있으며. 온라인 개인 커뮤니티 몰입 수준이 높을수록 원천 기업에 대한 반응은 좋게 나타나는 것을 알 수 있었다. 따라서 소비자들의 개인적 동일시와 사회적 동일시를 높여주기 위해서 온라인 개인 커뮤니티내의 상호작용 활동 및 정보제공의 용이성과 개인의 포현력을 높여줄 아이템의 개발이 있어야만 할 것이다.

핵심개념: 개인 커뮤니티 몰입, 개인적 동일시. 사회적 동일시, 개인적 실제자아 표현, 개인적 이 상자아 표현, 사회적 실제자아 표현, 사회적 이상자아 표현

\section{I. 서 론}

20세기 기업 환경에 있어 중요한 변화는 소비

* 전북대학교 경영학부 교수(cnh@chonbuk,ac,kr)

** 전북대학교 경영학부 박사과정(peterfan@chonbuk.ac.kr)
자의 권리 및 의견이 매우 중시되고 있으며, 이 러한 현상이 지속적으로 증대되고 심지어 기업 의 운명도 좌우하고 았다는 것이다. 이러한 소 비자 활동의 증대는 컴퓨터와 기술의 발전에 
의해 가능해졌고, 기업에게 새로운 기회를 제공 하게 되었다(김지화, 조효래 1997). 즉, 온라인 을 통하여 소비자들의 의견 및 불만 사항들의 수럼이 과거에 비해 수월해지고 적은 노력과 자원 투입으로 변화하는 소비자들의 트렌드를 쉽게 파악함으로써 시장의 세분화 및 충성도 높은 고객을 확보할 수 있는 기회가 될 수 있 다(Griffin 1996). 그리고 기업의 충성도 높은 고객 유치 및 기업에 대한 몰입을 위한 온라인 의견수렴에 중요한 역할을 하고 있는 온라인 커뮤니티의 경우 통합 마케팅 커뮤니케이션 (integrated marketing communication) 전략을 중시하고 있는 현대 기업에 있어 중요한 영역 을 담당하고 중요도 또한 증가하고 있는 실정 이며(Yohe 1994), 지속적으로 확대될 전망이다 (Valtersson 1998).

그러나 온라인 커뮤니티가 기업 전략에 있어 매우 중요한 역할을 차지하고 온라인 커뮤니티 의 활성화를 위해 지속적으로 투자가 이루어지 고 있음에도 불구하고 온라인 커뮤니티에 관한 선행 연구에는 새로운 특성들에 대한 연구 (Newhagen and Rafaeli 1996), 가상공간과 오 프라인에서 발생하는 다양한 현상들의 차별적 특성에 관한 연구(Park and Floyd 1996), 문화 및 권력에 대한 연구(이오현 2003), 개인 커뮤 니티 동일시 요인에 관한 연구(서문식, 김유경 2003), 개인 커뮤니티 이용 동기 및 원천 몰입 에 관한 연구(양석준, 박유진 2005) 등이 있고. 개인 커뮤니티에 대한 자아와 동일시 관련 연 구는 매우 부족하다. 개인 커뮤니티는 미니홈피 를 매개로 형성된 커뮤니티이며, 미니홈피는 이 용자들 상호간에 의견을 교환하고, 자신의 자아 를 표현하며, 대인관계를 유지하고 확충하는 매
체이다. 그런데 온라인 개인 커뮤니티 활성화의 첫 번째 단계라고 할 수 있는 온라인 개인 커 뮤니티 몰입에 있어서의 자아표현의 역할에 관 한 연구는 아직까지 이루어지지 않고 있다.

소비행동에는 자아개넘을 구성하고 개인적 아이텐티티를 창조하려는 측면이 있다(Richins 1994). 즉 소비자는 제품을 사용하여 원하는 아이텐티티를 구성하고 표현한다(Escalas and Bettman 2005). 일반적으로 소비자들은 제품이 나 서비스 및 브랜드의 이용을 통하여 다른 사 람에게 자신을 표현하며 그런 가운데 자아규정 의식(sense of self-identification)을 느끼게 되 고 자아 이미지를 잘 반영하고 표현할 수 있는 제품이나 서비스 혹은 브랜드에 동일시를 느끼 고, 그 제품이나 서비스 혹은 브랜드를 선호하 게 된다고 할 수 있으며(Rio et al. 2001), 동일 시가 이루어지는 과정에 있어 이상적 자아와 실제적 자아가 영향을 미친다(Graeff 1996).

미니홈피는 자신의 아이텐티티를 구성하고 표 현하는 매체이다. 따라서 개인 커뮤니티에도 동 일시과정이 적용될 수 있다고 보고, 이 연구는 개인 커뮤니티에서 자아를 포현하는 활동을 하 는 소비자들에게 자신의 자아 이미지와 유사한 개인 커뮤니티에 대해 동일시가 쉽게 일어나고 쉽게 몰입할 수 있으며. 원천기업에 관한 활동 또한 지속적으로 할 수 있다고 가정한다. 온라 인 개인 커뮤니터 몰입에 있어 미니홈피를 통 한 커뮤니티에 대한 자아표현이 동일시에 매우 중요한 것을 예측할 수 있는데, 자아표현의 동 일시 효과성에 관한 연구는 이루어지지 않고 있다.

따라서 본 연구에서는 첫 번째로 개인 커뮤니 티 몰입에 영향을 미치는 요인으로서 동일시의 
역할을 살펴보고, 두 번째로 동일시에 영향을 미치는 미니홈피를 통한 자아표현의 역할을 살 펴본다. 그리고 마지막으로 온라인 개인 커뮤나 티 몰입이 원천기업에 대한 긍정적 반응에 미 치는 영향을 탐색한다.

\section{II. 이론적 배경과 연구 가설}

\section{1 자아와 자아표현}

자아 개념은 사회 환경과 연계성을 설명할 수 있는 자아다양성(multiple selves)의 관점에서 접근되고 있다. 심리학적 입장에서 자아는 단지 개인 속성간의 집합적 개념이 아닌 더 넓은 개 념으로 인식되고 있으며. 지속적으로 조명이 되 고 있다(Gergen 1981; Niedenthal and Beike 1997). 최근 구조적 입장에서의 자아는 다른 사 람들과 자신을 연결하고 정의내리는 관점에서 사용되고 있으며, 문화적, 집합적 구성 개념들 을 포함하는 넓은 의미로써 사용되고 있다 (Tajfel and Turner 1979; Triandis 1989). 그 리고 자아 근원에 관한 연구 대부분이 Tajfel and Turner(1979)의 사회적 아이덴티티 이론을 기본으로 자아를 개인적 아이덴티티와 사회적 아이덴티티로 구분하거나 이를 더 확대시켜 자 아-범주화 이론을 통하여 자아를 살펴보고 있 다(Tajfel and Turner 1979; Turner, Hogg, Oakes, Reicher, and Wetherell 1987). 그리고 $\operatorname{Sirgy}(1982,1985)$ 는 자아-개넘(self-concept)을 실제자아이미지(actual self-image), 이상자아이 미지(ideal self-image), 사회자아이미지(social self-image), 그리고 이상사회자아이미지(ideal social self-image)로 구분하고, ”실제자아이미지 "는 소비자가 그들 스스로를 어떻게 보는 지로 정의되고, "이상자아이미지"는 소비자가 그들 스스로를 어떻게 보기를 원하는 지로 정의되며, "사회자아이미지"는 소비자가 다른 사람에게 어떻게 보여지는 지. "이상사회자아이미지"는 소비자가 다른 사람에 의해 어떻게 보여지기를 원하는 지로 정의될 수 있다고 보고 있다.

그런데 소비자에게는 제품의 사용을 통하여 자신을 표현하고자 하는 욕구가 있다(Mittal et al. 1990), 소비자들은 제품을 통하여 자신의 개 성이나 자아 또는 라이프 스타일, 사회적 지위 나 신분 등을 표현하고자 한다. 그리고 소유물 (possessions)은 자신의 자아개넘을 능동적으로 창조하고, 자아 아이덴티티를 강화하고 표현하며, 자신을 차별화하고, 개인적 특성(individuality) 을 주장하려는 심리적 욕구를 충족시키는 데 사용된다(Kleine, Kleine, and Allen 1995). 또 한 소유물은 가족, 커뮤니티, 그리고 문화집단 등에 대한 사회적 결속을 반영하여 사회적 목적 달성에 기여하기도 한다(Muniz and $O^{\prime}$ Guinn 2001). 개인적 소유물로서 개인적 미니홈피는 자아개념을 창조하고 규정하기 위하여 사용되 는 상징적 의미를 내포하고 있다. 따라서 본 연 구에서는 개인 커뮤니티를 이용하는 소비자들 은 실제적 자아와 이상적 자아를 개인 미니홈 피에 표현하고 반영한다고 본다.

\section{2 동일시}

사회 심리적인 관점에서 시작된 동일시 (identification) 연구들의 대부분은 조직 분야에 
서 주로 이루어지고 있으며, 사회 정체성 이론 에 그 기반을 두고 있다(Dutton, Dukerish, and Harquail 1994, Mael and Ashforth 1992). Bell and Bulent(2002)은 사회 정체성 이론이 자아 개념(self-concept)의 핵심적 위치를 차지하고 있 으며, 사회적 범주에 대한 멤버십(social category membership)이 사회적 환경 속에서 상호작용 하는 개인들의 지각과 행동에 영향을 미친다 고 보고 있다. 그리고 Dutton, Dukerish, and Harquail(1994)은 자아 개념을 개인 정체성과 다양한 사회 정체성으로 구분하고 어떤 개인 혹은 집단과 동일시가 이루어진다는 것은 그 개인 혹은 집단과 관련된 정체성이 자아 개념 에서 주도적인 역할을 수행하고 이러한 과정에 서 자아 정의(self-definition) 가 이루어지고 이 러한 자아정의 과정을 동일시라고 정의하고 있 고 개인 동일시는 집단 동일시와 상호보완적인 역할을 수행한다. 이러한 동일시에 관한 연구들 의 경우 동일시에 영향을 주는 요인에 관한 연 구(Bhattacharyam, Rao, and Glynn 1995), 동 일시가 조직에 미치는 연구(Mael and Ashforth 1992), 계층적 조직에 속한 사람들의 각 조직에 대한 동일시와 커뮤니케이션 촉진에 관한 연구 (Fisher and Sonn 1999) 등으로 구분될 수 있 다. 또한 온라인 환경에서의 동일시 연구들은 사회적 동일시, 커뮤니티 동일시가 자기 범주화 이론을 위해 새로운 프레임웍을 제공한다는 연 구(Lantz and Sandra 1998), 사회적 동일시에 의해 하나의 공동체로서의 역할을 하는 웹사이 트에 대한 동일시가 발생한다는 연구(Frank and Sugiyama 2001), 사회적 동일시가 웹사이 트에서의 커뮤니케이션 빈도를 높인다는 연구 (Stole 2002), 가상 공동체 의식이 높을수록 웹
사이트 충성도가 증가한다는 연구(박성연, 유승 현 2003) 등으로 구분될 수 있는데, 온라인 환 경에서의 동일시 연구 대부분은 사회적 동일시 에 관한 연구들이 주류를 이루고 있다고 볼 수 있다. 그러나 소비자들이 어떤 제품이나 서비스 를 소비할 경우 '자아-규정 의식(sense of self-definition)'을 느끼며 잘 반영하는 제품이 나 서비스에 대해서 커뮤니케이션이 증가하고 자아 개념이 개인적 아이덴터티와 사회적 아이 덴티티로 구분된다면, 동일시도 개인적 동일시 와 사회적 동일시로 구분될 수 있음에도 불구 하고 선행연구들은 대부분이 사회적 동일시의 영향요인과 결과요인들에 초점을 맞추고 있다. 특히 개인적 동일시의 고객관련 행동에 관한 연구는 이유재, 라선아(2002)의 연구에서만 다 루고 있는 실정이다. 따라서 본 연구에서는 동 일시를 개인적 동일시와 사회적 동일시로 구분 하고 개인 커뮤니터에 대한 동일시의 역할을 탐색한다.

\subsection{1 개인 미니홈피에서 자아표현과 개인 커뮤니티동일시의 관계}

우리들의 자아 개념 또는 정체성은 우리들의 감정, 생각, 행동 그리고 우리가 이루려고 하 는 목적에 많은 영향을 미친다고 할 수 있다 (Leary and Tangney 2003). 자아 개념은 "개인 이 자신을 대상으로 해서 가지는 생각이나 감 정의 총체'라고 할 수 있으며(Rosenberg 1979), 자신의 행동과 기억에 의미를 부여하고 조직화 시키는데 용이한 지식 구조라고 할 수 있다 (Kihlstorm, Beer, and Klein 2003). 예를 들어. 일정 정보가 자아와 관련되어 있을 경우 기억 
이 용이하게 되며, 자아와 관련된 정보는 다른 정보에 비해 더욱더 체계적으로 구축된다고 볼 수 있으며, 이러한 자아는 다른 사람들과의 사 회적 상호작용으로서의 기능을 수행한다고 볼 수 있다(Lord and Brown 2004). 즉, 자아라는 것이 단일 차원이 아닌 다차원적 성격을 지니 고 있다는 것이다.

개인의 전반적 자아는 차별적 자아 또는 정체 성으로 각각 표현되는 범주화군으로서 표현된 다(Markus and Wulf 1987). 이러한 차별적 자 아 또는 정체성은 특별한 사회적 맥락에 따라 달라지며, 개인적 위치(personal positions)와 사 회적 위치(social positions) 또는 독특한 사회적 맥락에서의 역할 관계에 따라 자아가 결정될 수 있으며, 이러한 자아의 결정은 결국 자아 현 저성(self-salient)에 의해서 결정된다고 할 수 있다. 만약 자아가 동적이면서 자아 현저성에 의해서 결정된다면 자아 개념은 상황에 따라 종속적인 형태를 지닌다고 할 수 있다(van Knippenberg et al. 2000). 전반적 자아 개념의 활성화는 특별한 시간, 정보처리과정, 감정 그 리고 행동에 따라 달라지고 이렇게 할성화된 자아 개념에 따라 자아 개념에 적합한 행동이 유발된다(Lord and Brown 2004). 상황에 따라 달라지는 자아를 구분하는 자아 범주화, 자아 구성, 사회적 정체성 이론들은 자아가 다른 사 람과의 차별적 특성으로 구분될 뿐만 아니라 (개인적 자아), 집단적 수준에서 사회적 아이덴 티티(Hogg 2003) 또는 사회적 자아(Brewer and Gardner 1996)의 현저성에 의해서도 구분 된다.

브랜드 신념(brand beliefs)의 기초가 되는 혜 택(benefits)은 소비자가 브랜드에 부여하는 개
인적 가치이고 의미이다(Keller 2003). 그리고 브랜드 신념은 소비자가 광고의 주장을 처리할 때 산출되는 브랜드 인지(brand cognition)와 유사한 개념이다(Kempf and Smith 1998). Keller(2003)와 Park, Jaworski, and MacInnis (1986)는 브랜드 신념을 기능적(functional)신 념, 경험적(experiential)신념, 상징적 (symbolic) 신넘으로 구분하였다. 기능적 신념은 웰빙, 건 강과 같은 기본적인 동기와 관련되며, 경험적 신념은 브랜드의 사용에서 느끼는 감정과 관련 되고, 감각적 쾌락(sensory pleasure)과 인지적 자극과 같은 경험적 옥구를 충족시키는 혜택과 관련된다. 상징적 신념은 사회적 승인(social approval), 개인적 표현(personal expression), 외부 지향적 자아 존중감(outer-directed selfesteem)의 욕구에 기반이 되는 소비의 외재적 이익(extrinsic advantages) 과 관련된다.

이 연구는 개인 커뮤니티에 대해서 미니홈피 를 통해 개인적 표현, 사회적 승인 등의 외재적 이익을 얻으려는 상징적 신념과 관련된다. 소비 자에게는 제품의 사용을 통하여 자신을 표현하 고자 하는 욕구가 있다(Mittal et al. 1990). 개 인은 자신의 미니홈피를 통하여 개인적 자아를 표현할 수 있고 또 타인과 상호작용 할 수 있 으며, 자아존중감 욕구를 충족시킬 수 있다.

실제자아이미지와 이상자아이미지는 소비자 자신이 자신을 어떻게 보는가와 관련된 자신의 지각(perception)이다. 소비자는 자신의 행동이 그들의 자아를 입증하는 피드백 과정을 통하여 자신의 행동을 하여 자아개념을 유지하려 한다. Schlenker(1980)와 Swann(1990)은 특정 제품 및 브랜드 혹은 서비스를 이용하는 소비자들은 자신들의 자아를 유지하기 위하여 자아 확증적 
증거를 찾고 자아 확증적 사회 환경을 개발하 여 타인의 반응에 영항을 미치려고 노력하는 자아 확증 욕구를 지니고 있다고 보고 있다.

개인은 미니홈피를 통하여 개인적 자아를 유 지할 수 있는 증거를 표현하고 또 자신의 자아 가 존중될 수 있는 미니홈피의 개발을 통하여 자신의 품격을 높일 수 있고 또 자신의 만족감 을 얻을 수 있다. 따라서 개인 커뮤니티에 개인 적 자아유지를 위한 표현수준이 높을수록 개인 적 동일시수준은 높아질 것이다.

자아 개념이 그들의 가족 및 친구와 같은 관 계에서의 개인적 역할에 기반하여 개인화 될 경우 개인적 존재의 입증 및 향상을 위해서 노 력을 하게 되는데(Sedikids and Brewer 2001), 개인 커뮤니티에 자신의 긍정적 이미지를 표현 할 수 있다면 이로 인해 개인 커뮤니티예 대한 개인적 동일시 수준은 높아질 것이다.

그리고 사회자아이미지와 이상사회자아이미지 는 타인이 자기 자신을 어떻게 보고, 또 보기를 원하는가에 대한 자신의 지각이다. Schlenker (1980)와 Swann(1990)은 자아를 입증하기 위 하여 (1) 자아확증적 증거를 찾고 (2) 자아확 증적 사회환경을 개발하여 타인의 반응에 영향을 미치려고 노력한다고 하였다. 그리고 Setterlund and Niedenthal(1993)은 사람들은 선택군내의 각 대체안에 대한 전형적인 사용자를 상상하고, 바람직한 전형적인 사용자와 가장 유사해질 수 있는 대체안을 선택한다고 하였다. 즉 자신을 전형적인 어울림(ptototype matching) 휴리스 틱에 의해서 전형적인 사용자에 매취시켜 자신 도 전형적인 사용자 이미지에 부합됨을 보여주 는 자아표현 방법을 선택한다. 따라서 개인 커 뮤니티에 실제 사회자아를 표현할 수 있으면
사회적 동일시 수준은 높아질 것이다.

보통 사람들은 높은 자아존중감을 갖는 경우 에 자신의 인상(impression)을 신중하게 관리한 다. 이렇게 자아존중감이 높은 사람들은 자아존 중감을 얻기 위한 자아 고양 욕구가 높으며, 자 신의 표현을 상황에 따라 관리하여 피드백의 긍 정성을 극대화시키기 위해서 노력한다(Schlenker 1980). 소비자는 심리적으로 타인과 연관을 가 지려는 사회적 옥구를 가지고 있으며, 따라서 특정집단의 규범, 가치, 행동을 받아들이고 타 인이 원하는 자아이미지를 강화하고 또 자신이 존경하는 타인들과 일치감을 추구한다. 또한 자 아에 대한 그룹의 영향이 크면 집단 및 제품에 대한 사회적 동일시는 쉅게 일어날 수 있다 (Ridgeway and Balkwell 1997). 따라서 개인 커뮤니티에 타인과 관련된 자신의 이상적 사회 자아의 표현수준이 높을수록 사회적 동일시 수 준은 높아질 것이다.

가설 1: 개인 커뮤니티에서 개인적 실제자아 표현수준이 높을수록 개인적 동일시 는 높아질 것이다.

가설 2: 개인 커뮤니티에서 개인적 이상자아 표현수준이 높을수록 개인적 동일시 는 높아질 것이다.

가설 3: 개인 커뮤니티에서 사회적 실제자아 표현수준이 높을수록 사회적 동일시 는 높아질 것이다.

가설 4: 개인 커뮤니티에서 사회적 이상자아 표현수준이 높을수록 사회적 동일시 는 높아질 것이다. 
McMillan and Chavi(1986)의 커뮤니티 이론 에 의하면 커뮤니티에 관한 동일시는 커뮤니티 를 인식하는 심리적 기제의 중요한 영역을 차 지하고 있다. 특히, 동일시는 커뮤니티 구성원 으로서의 역할을 수행하게 하거나 다른 커뮤니 티 구성원들과 감정적 연결을 시켜 커뮤니티에 대한 책임감과 몰입을 이끌어 내는 역할을 한 다(Obst and White 2005).

온라인 커뮤니티 동일시 수준은 커뮤니티에 대한 구성원 개인들의 아이덴티티의 정도에 따 라 달라질 수도 있으며 온라인 커뮤니티에 대 한 사회적 동일시에 의해서도 달라질 수 있다 (Fisher and Sonn 2002; Smith, Zinkiewicz, and Ryall 1999).

온라인 커뮤니티에 대한 개인적 동일시는 소비 자가 온라인 커뮤니티에 대해 유사성(affinity) 를 지님으로써 시작되며(Rio et al. 2001), 자 아 이미지와 온라인 커뮤니티 이미지가 일치 (image-congruence)하고, 온라인 커뮤니티를 통해 자아 이미지의 표출 및 향상이 이루어질 경우, 해당 온라인 커뮤니티에 대한 평가는 더 욱더 좋아지고 해당 커뮤니티에 대한 정보 제 공 및 상호작용 효과는 증가하여, 결과적으로 온라인 커뮤니티에 대한 몰입이 증가한다고 할 수 있다(Fisher and Sonn 2002: Graeff 1996). 따라서 온라인 개인 커뮤니티에 대한 개인적 동일시는 개인 커뮤니티에 대한 몰입수준을 높 일 것이다.

가설 5: 개인 커뮤니티에 대한 개인적 동일 시 수준이 높을수록 개인 커뮤니티
그리고 Smith et al.(1999)은 그룹내 동일시 와 온라인 커뮤니티 동일시에 대한 심리적 지 각에 대해서 조직에 대한 사회적 동일시 이론 들을 이용하여 설명하고 있다. 그들은 사회적 동일시가 커뮤니티에 대한 심리적 지각 수준을 더욱더 높여줄 수 있으며, 이를 통해서 온라인 커뮤니티에 대한 전반적 인식과 몰입을 이끌어 널 수 있다고 보고 있다. 이러한 연구 결과는 동일시와 온라인 커뮤니티에 대한 심리적 지각 이 뚜렷하게 구분되고 있음에도 불구하고 두 개념간에 관계가 강하게 연관되어 있음을 의미 한다고 할 수 있다(Obst and White 2005). 따 라서 사회적 동일시 이론들을 이용하여 동일시 와 온라인 커뮤니티에 대한 심리적 지각뿐만 아니라 온라인 커뮤니티에 대한 몰입 정도와 그룹내의 관계, 그리고 그룹의 작용 과정 등을 설명할 수 있다. 즉, 사회적 동일시 이론들은 커뮤니티의 구성원이 커뮤니티에 감정적 동조 를 강하게 인식하고 강한 가치를 부여할 경우 커뮤니티에 대한 강한 동일시가 이루어지며, 이 러한 커뮤니터 동일시는 커뮤니티에 대한 몰입 과 같은 감정적이고 인지적인 결과를 동반할 수 있다고 보고 있다(Obst and White 2005). 따라서 다음과 같은 가설을 설정할 수 있다.

가설 6: 개인 커뮤니티에 대한 사회적 동일 시 수준이 높을수록 개인 커뮤니티 에 대한 몰입 수준은 증가할 것이다. 


\section{4 개인 커뮤니티 몰입과 원천기업에 대한 긍정행동}

원천기업에 대한 소비자의 긍정적 행위 반응 은 아직까지 명확하게 정의되어 있는 것은 아 니지만 안광호와 이건호(2004)의 기업에 대한 긍정적 행위 반응에 대한 정의를 근거로. 원천 기업에 대한 충성도, 긍정적 구전, 적극적 대응(resilience to negative information)이라고 정의 한다. 이러한 원천기업에 대한 소비자의 긍정적 행위 반응은 온라인 상황에서 개인들이 온라인 커뮤니티의 규범과 일치하는 행동이나 의도를 보여주는 것으로써 온라인 커뮤니티 몰입과 직 접적으로 연관되어 있다 (McAlexander, Schouten, and Koenig 2002; Muniz and O'Guinn 2001). 즉 온라인 커뮤니티는 오프라인의 커뮤니티와 다르게 커뮤니티 전환이 용이하기 때문에 온라 인 커뮤니티를 이용하는 사람들은 온라인 커뮤 니티에 대한 감정적 몰입을 통하여 상호간의 관계 이익과 발전을 위한 노력을 지속적으로 할 것이며(Kumar, Hibbard, and Stern 1994),
개인커뮤니티에서 구성원들간의 커뮤니케이션 의 증가가 커뮤니티에 대한 일체감 및 소속감 을 유발하며 규범적 몰입이 높아진 사람들은 온라인 커뮤니티가 외부적 영향을 되도록 적게 받고 지속적으로 유지 발전되도록 노력하는 경 향이 강하게 나타난다(Gruen et al. 2000). 이 러한 관점에서 개인 커뮤니티에 대한 몰입은 원천기업의 규범에 적응을 유도하고 상호간에 이익과 발전을 위한 노력을 유도할 것이다. 따 라서 다음과 같은 가설을 설정할 수 있다.

가설 7: 개인 커뮤니티 몰입 수준이 높은 소 비자는 원천기업에 대한 긍정적 반 응을 할 것이다.

이상의 가설을 통해 〈그림 1)과 같은 연구 모 형을 설정할 수 있다.

\section{〈그림 1〉 본 연구의 모형}

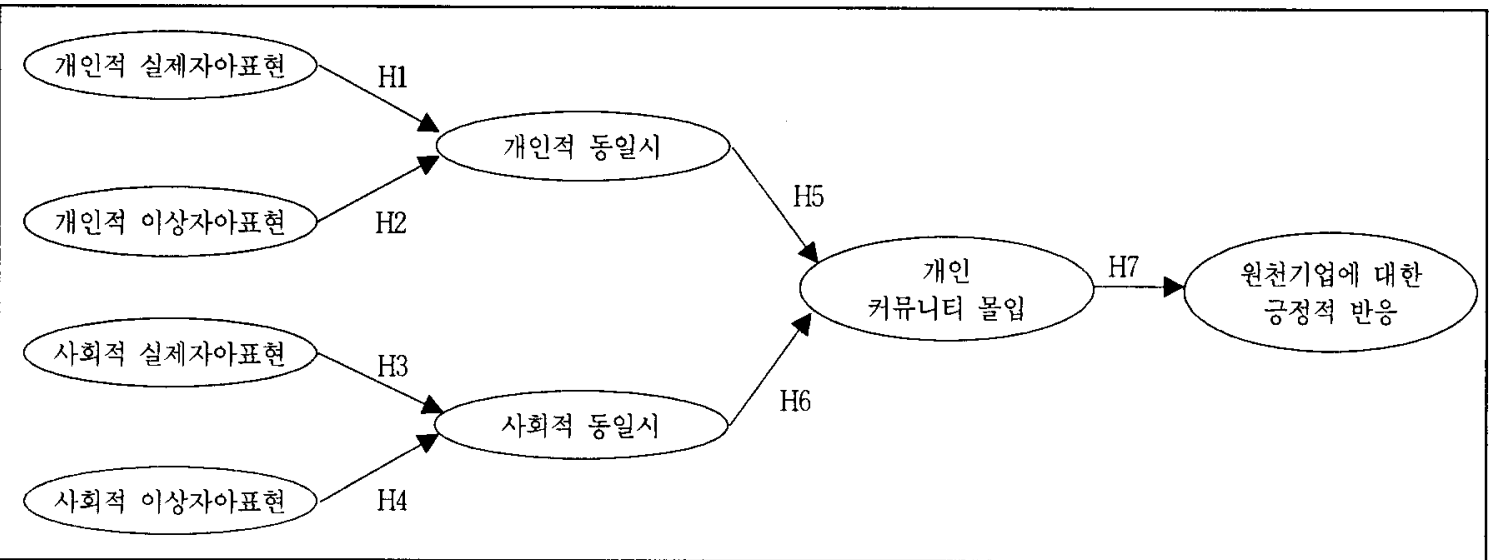




\section{III. 측정과 자료수집}

\section{1 구성 개념의 조작적 정의}

본 연구에 사용된 구성 개념들을 측정하기 위 한 항목들은 7 점 척도를 이용한다 $(1=$ 전혀 그 렇지 않다. $7=$ 매우 그렇다). 개인적 자아표현 에 대한 측정에는 시각적 디자인, 실제모습의 사진, 청각적 음악, 그리고. 인지와 감정의 관 점에서 글과 감정표현 등이 이용되고, 사회적 자아표현에는 대인관계, 안부인사, 사회적 승인 등의 표현을 이용하였다. 그리고 조사대상은 온 라인 개인 커뮤니티 서비스를 제공하는 싸이월 드를 이용하고 있는 소비자로 하였다.

\section{1 .1 개인적 실제자아 표현}

온라인 커뮤니티에서 개인적 실제자아 표현은 홈피의 관계요소에 의한 개인적 자아의 표현욕 구의 충족정도이다. 본 연구에서는 개인 미니홈 피에 개인적 실제자아 표현 문항으로, '나의 미 니홈피는 나의 실제 자아를 디자인으로 반영해 서 좋음', '나의 미니홈피가 나의 기분이나 감정 을 반영해서 좋음', '나의 미니홈피는 나의 실제 모습의 사진을 올릴 수 있어 좋음 등의 3 개 문 항으로 측정하였다.

\section{1 .2 개인적 이상자아 표현}

온라인 개인 커뮤니티에서 개인적 이상자아 표현은 홈피의 관계요소에 의한 개인적 이상자 아의 포현욕구의 충족정도이다. 따라서 개인 미
니홈피에 개인적 이상자아 표현을 측정하는 문 항으로. 개인의 긍정적 이미지 표현에 역점을 두고, 글, 디자인, 음악 등의 요소에 대하여, '나 의 미니홈피는 글을 통해 나의 긍정적 이미지 를 반영해서 좋음', '나의 미니홈피는 내가 꾸며 놓은 디자인을 통해 나의 긍정적 이미지를 표 현해서 좋음', '나의 미니홈피는 음악 성향을 통 해 나의 긍정적 이미지를 반영해서 좋음 등의 3 개 문항으로 측정하였다.

\subsection{3 사회적 실제자아 표현}

온라인 커뮤니티에서 사회적 실제자아 표현은 홈피의 관계요소에 의한 사회적 자아의 표현욕 구의 충족정도이다. 사회적 실제자아표현을 측 정하기 위해서, 양석준과 박유진(2005)의 대인 관계동기측정문항을 동기충족의 관점에서 보완 하여, 대인관계 용이성. 안부인사, 관계확충 등 을, '나의 미니홈피를 통해 아는 사람들과 관계 형성이 용이해서 좋음', '나의 미니홈피를 통해 친구나 아는 사람들과의 관계가 원만하게 되어 좋음', '나의 미니홈피를 통해 친구나 아는 사람 들과 안부 인사를 할 수 있어 좋음', '나의 미니 홈피를 통해 사람들과의 인간관계를 넓혀서 좋 음 등의 4 개 문항으로 측정하였다.

\section{1 .4 사회적 이상자아 표현}

온라인 커뮤니티에서 사회적 이상자아 표현은 홈피의 관계요소에 의한 사회적 이상자아의 표 현욕구의 충족정도이다. 사회적 이상자아표현을 측정하기 위해서 타인에 대한 자신의 긍정적 이미지, 사회적 승인, 대인관계 원만성 표현 등 
을, '나의 미니홈피를 통해 사람들에게 나를 긍 정적으로 보일 수 있어 좋음', '나의 미니홈피를 통해 내가 인정받을 수 있어 좋음', '나의 미니 홈피를 통해 사람들과의 관계가 원만함을 긍정 적으로 보일 수 있어 좋음 등의 3개 문항으로 측정하였다.

\section{1 .5 사회적 동일시}

사회적 동일시는 개인이 감정적으로 중요하고 가치 있다고 여기는 집단과의 멤버십을 통하여 평가하는 과정이라고 정의 할 수 있다(Tajfel and Turner 1979). 본 연구에서는 사회적 동일 시를 측정하기 위해서 Ashforth and Mael(1989), Bergami and Bagozzi(2000), Bhattacharya and $\operatorname{Sen}(2003)$ 에서 이용되었던 측정 변수들을 수정 하여, "싸이월드의 나의 미니홈피의 구성원들이 나와 동일시됨', '친구 및 동료에게 나의 싸이월 드 미니홈피는 좋은 커뮤니티라고 인식됨', '친 구 및 동료들은 싸이월드의 나의 미니홈피 서 비스를 호의적으로 봄' 등의 3 개 문항을 이용하 여 측정하였다.

\section{1 .6 개인적 동일시}

개인적 동일시는 제품 및 서비스의 이미지가 응답자 자신의 자아이미지에 얼마나 일치하는 지의 정도라고 정의할 수 있다(이유재, 라선아 2002). 본 연구에서는 개인적 동일시를 측정하 여 위해서 이유재, 라선아(2002)가 이용하였던 측정 변수들을 수정하여 '싸이월드의 나의 미니 홈피는 나의 가치관에 잘 맞음', '싸이월드의 나 의 미니홈피 이미지는 나의 라이프스타일에 잘
맞음 등의 2 개 문항을 이용하여 측정하였다.

\subsection{7 개인 커뮤니티 몰입}

온라인 커뮤니티 몰입은 개인 홈피나 블로그 와 관련된 커뮤니티에 대한 상호작용의도(신종 칠 1999)이며 지속적인 충성도(송창석 1997)라 고 할 수 있다. 본 연구에서는 온라인 커뮤니티 몰입의 선행연구(송창석 1997; 신종칠 1999; 양석준, 박유진 2005)를 기반으로, '나의 미니홈 피 커뮤니티가 맘에 듬', '나의 미니홈피에 자주 방문할 의사가 있음', '나의 미니홈피 커뮤니티 를 소중하게 생각함' 등의 3 개 문항을 이용하여 측정하였다.

\section{1 .8 원천기업에 대한 긍정적 반응}

소비자의 긍정적 행위 반응은 특정 기업의 제 품 및 기업 정보에 대해 소비자들이 보이는 행 동 성향 및 구체적 행동으로(안광호, 이건희 2004), 본 연구에서는 소비자 반응의 선행 연구 (안광호, 이건희 2004)를 참고로, '싸이월드 싸 이트에 자주 방문할 의사가 있음', '다른 사람에 게 싸이월드의 긍정적 면을 말할 의사가 있음 등의 2 개 문항을 이용하여 원천기업에 대한 긍 정적 반응을 측정하였다.

\section{2 자료의 수집}

본 연구의 설문 개발은 관련 논문들의 종합적 인 검토를 통해서 이루어졌으며, 본 연구에서 사용된 조작적 정의의 기초 하에 설문을 작성 하고 마케팅 및 MIS 전공의 박사과정생과 현 
재 싸이월드를 이용하고 있는 대학생 및 대학 원생들을 대상으로 1차 사전조사를 실시하였다. 그리고 이들의 의견 및 수정사항을 참고하여 본 조사가 실시되었으며, 본 조사는 2006년 9 월 4 일부터 15 일까지 설문조사로 실시하였으 며, 싸이월드를 이용하고 있는 사람들을 대상 으로 총 320 부의 설문지를 배부하였다. 배부된 설문지 중 300 명으로부터 설문을 회수하였으 며, 이중 응답 불성실 및 오류가 발생한 설문 지를 제외하고 299 부의 설문지를 최종 분석에 이용하였다.

\section{3 응답자 특성}

본 연구를 위해 설문에 응답한 남녀의 비율은 남성이 $35.5 \%$, 여성이 $64.5 \%$ 였으며, 연령대는 20세-30세가 93.1\%로 압도적인 모습을 보이고 있었다. 이는 미니홈피를 주로 이용하는 소비자 들의 특성을 반영하는 결과라고 할 수 있으며, 미니홈피 이용경험은 1 년 이하가 $50.5 \%, 1$ 년-2 년이 $24.4 \%$ 로 나타났다.

\section{N. 분석결과}

\section{1 신뢰성과 타당성 평가}

본 연구 모델을 검증하기 위해서 각 요인별 측정 항목들의 신뢰도(reliability)를 검증하였으며, 이러한 결과를 기초로 Anderson and Gerbing (1988)의 분석방법을 이용하여 연구 모델을 검 증하였다. 외생변수 및 내생변수들의 내적 일관 성(internal consistency)를 조사하기 위해서 Cronbach's a를 조사하였는데, 개인적 실제자아 표현 $(\mathrm{a}=.744)$, 개인적 이상자아 표현 $(\mathrm{a}=.749)$, 사회적 실제자아 표현 $(\mathrm{a}=.844)$, 사회적 이상자 아 표현 $(a=.906)$, 개인적 동일시 $(a=.803)$, 사 회적 동일시 $(\mathrm{a}=.863)$, 개인 커뮤니티몰입 $(\mathrm{a}=$ 837), 원천기업에 대한 긍정적 반응 $(\mathrm{a}=.769)$ 으로서 모두 일반적 허용치인 0.7 를 상회하고 있어(Bagozzi and Yi 1988), 측정변수들의 신뢰 성은 입증되었다(〈표 1〉참조).

또한 측정 변수들의 수렴 타당성(convergent validity)을 검증하기 위해서 탐색적 요인분석 을 실시한 결과 수렴 타당성 또한 입증되었으 며(〈표 1〉참조), 탐색적 요인분석 결과를 확증 하기 위하여 Anderson and Gerbing(1988)이 제시하였던 방법에 따라 확인적 요인분석을 실 시한 결과 모형의 적합도 또한 $x^{2}=392.519$ $(\mathrm{p}=0.00), \quad \mathrm{GFI}=0.900, \quad \mathrm{AGFI}=0.864, \quad \mathrm{CFI}=0$ .984, RMSEA $=0.0544, \mathrm{NFI}=0.968$ 으로 나타나 대체적으로 우수하였다. 또한 연구 단위의 표준 요인 부하량의 $\mathrm{t}$ 값이 모두 2 보다 큰 값을 나타 내어 본 연구의 측정모델은 집중타당도가 있는 것을 알 수 있었다(〈표 2〉참조).

한편, 실증 분석에 투입될 제 요인들의 판별 타당성(discriminant) 을 확보하기 위해서는 첫 째, 구성개념간 상관관계를 보여주는 $\phi$ 계수의 신뢰구간 $(\Phi \pm 2 \mathrm{~s} . \mathrm{e})$ 에 1.0 이 포함되지 않아야 한 다. 둘째, 2 개 구성개념으로 짝지워진 모든 쌍 에 대하여, 상관계수를 1 로 제약시킨 측정모델 과 비제약 모델 간에 $x^{2}$ 값 차이가 유의한지를 살펴보아야한다. 셋째, 더 엄격한 테스트로서 평균추출분산(AVE)이 모든 구성개념 간 상관 자승치보다 큰지를 살펴보아야한다(Fornell and 
〈표 1〉 측정 변수들에 대한 요인분석 및 신뢰도 검증결과

\begin{tabular}{|c|c|c|c|c|c|c|c|c|}
\hline & \multicolumn{8}{|c|}{ Component } \\
\hline & SSS & SSE & OCC & SI & PSE & PSS & PI & $\mathrm{CR}$ \\
\hline $\begin{array}{l}\text { 나의 미니홈피를 통해 친구나 아는 사람들과의 관계가 원만해 } \\
\text { 서 좋음 }\end{array}$ & .751 & .210 & .153 & .089 & .102 & .130 & .185 & .115 \\
\hline 나의 미니홈피를 통해 사람들과의 인간관계를 넓혀서 좋음 & .749 & .171 & .206 & .047 & .275 & .165 & .029 & .143 \\
\hline $\begin{array}{l}\text { 나의 마니홈피를 통해 친구나 아는 사람들과 안부 인사롤 할 } \\
\text { 수 있어 좋음 }\end{array}$ & .743 & .253 & .056 & .002 & .180 & .165 & .051 & .035 \\
\hline 나의 미니홈피를 통해 아는 사람들과 관계형성이 용이해서 좋음 & .729 & .116 & .113 & .267 & .140 & .216 & .103 & -.024 \\
\hline 나의 미니홈피를 통해 내가 인정받을 수 있어 좋음 & .228 & .835 & .203 & .178 & .118 & .148 & .066 & .059 \\
\hline $\begin{array}{l}\text { 나의 미니홈피를 통해 사람들에게 나를 긍정적으로 보일 수 } \\
\text { 있어 좋음 }\end{array}$ & .259 & .807 & .140 & .259 & .122 & .123 & .106 & .050 \\
\hline $\begin{array}{l}\text { 나의 미니홈피를 통해 사람들과의 관계가 원만함을 긍정적으 } \\
\text { 로 보일 수 있어 좋음 }\end{array}$ & .253 & .767 & .155 & .204 & .260 & .063 & .112 & .113 \\
\hline 나의 미니홈피에 자주 방문할 의사가 있음 & .147 & .133 & .804 & .237 & .091 & .177 & .160 & .088 \\
\hline 나의 미니홈피커뮤니티가 맘에 듬 & .080 & .145 & .756 & .156 & .170 & .078 & .236 & -.044 \\
\hline 나의 미니홈피를 소중하게 생각함 & .237 & .213 & .749 & .275 & .118 & .070 & .032 & .179 \\
\hline 나의 미니홈피커뮤니티의 구성원들이 나와 동일시됨 & .127 & .177 & .299 & .773 & .136 & .085 & .205 & -.012 \\
\hline 친구 및 동료에게 나의 미니홈피는 좋은 커뮤니티라고 인식됨 & .108 & .204 & .214 & .728 & .351 & .111 & .086 & .029 \\
\hline 친구 및 동료들은 나의 미니홈피 서비스를 호의적으로 봄 & .134 & 314 & .271 & .695 & .158 & .043 & .164 & .044 \\
\hline $\begin{array}{l}\text { 나의 미니 홈피는 글을 통해 나의 긍정적 이미지를 반영해서 } \\
\text { 좋음 }\end{array}$ & .251 & .152 & .208 & .135 & .717 & .224 & .022 & -.015 \\
\hline $\begin{array}{l}\text { 나의 미니홈피는 음악 성향을 통해 나의 긍정적 이미지를 반 } \\
\text { 영해서 좋음 }\end{array}$ & .132 & .187 & .030 & .214 & .700 & .076 & .339 & .084 \\
\hline $\begin{array}{l}\text { 나의 미니홈피는 내가 꾸며 놓은 디자인을 통해 나의 긍정적 } \\
\text { 이미지를 표현해서 좋음 }\end{array}$ & .342 & .158 & .192 & .220 & .667 & .077 & .011 & .134 \\
\hline 나의 미니홈피가 나의 기분이나 감정을 반영해서 좋음 & .206 & .075 & .140 & .101 & .140 & .856 & .069 & .134 \\
\hline 나의 미니홈피는 나의 실제 자아를 디자인으로 반영해서 좋음 & .271 & .122 & .074 & .138 & .093 & 830 & .116 & .120 \\
\hline 나의 미니흠피는 나의 실제 모습의 사진을 올릴 수 있어 좋음 & .129 & .306 & .230 & -.255 & .188 & .656 & .348 & .133 \\
\hline 나의 미니홈피는 나의 가치관에 잘 맞음 & .140 & .184 & .246 & .377 & .094 & .142 & .765 & .007 \\
\hline 나의 미니흠피 이미지는 나의 라이프스타일에 잘 맞음 & .250 & .057 & .412 & .184 & .258 & .227 & .604 & .891 \\
\hline 싸이월드 싸이트에 자주 방문할 의사가 있음 & .227 & .103 & .427 & .109 & .282 & .246 & .258 & .891 \\
\hline 다른 사람에게 싸이월드의 긍정적 면을 말할 의사가 있음 & .193 & .146 & .158 & .028 & .108 & .248 & .098 & .843 \\
\hline Cronbach's a & 0.844 & 0.906 & 0.837 & 0.863 & 0.749 & 0.744 & 0.803 & 0.769 \\
\hline eigen value & 2.950 & 2.526 & 2.490 & 2.454 & 1.957 & 1.815 & 1.392 & 1.212 \\
\hline$\%$ of var. & 14.047 & 12.029 & 11.858 & 11.687 & 9.321 & 8.645 & 6.630 & 5.248 \\
\hline
\end{tabular}


Larcker 1981). (표 2)와 〈표 3〉에서 볼 수 있 듯이 평균추출분산(AVE)이 모든 구성개념 간 상관자승치보다 큰지를 살펴보았으며, 각각 의 구성 개념들간의 상관관계를 나타내는 $\Phi$ matrix를 확인적 요인 분석(confirmatory factor analysis)을 통하여 검토 하였다. 평균추출분산 $(\mathrm{AVE})$ 이 모든 구성개넘 간 상관자승치보다 큰지를 살펴본 결과 Fornell and Larcker(1981) 의 기준을 충족하는 것을 확인하였으며, 구성 개념들간의 상관관계를 나타내는 $\Phi$ matrix를

〈표 2〉연구 측정 변수들에 대한 확인적 요인분석 결과

\begin{tabular}{|c|c|c|c|c|}
\hline 개념변수 & 측정변수 & 추정계수 $(\lambda)$ & t값 & $\begin{array}{c}\text { 분산추출값 } \\
\text { (AVE) }\end{array}$ \\
\hline \multirow{3}{*}{ 개인적실제자아표현 } & PSS1 & 1.113 & 15.866 & \multirow{3}{*}{0.778} \\
\hline & PSS2 & 1.037 & 15.458 & \\
\hline & PSS3 & 0.786 & 8.972 & \\
\hline \multirow{4}{*}{ 사회적실제자아표현 } & SSS1 & 1.009 & 14.526 & \multirow{4}{*}{0.848} \\
\hline & SSS2 & 1.119 & 14.498 & \\
\hline & SSS3 & 0.938 & 14.215 & \\
\hline & SSS4 & 1.030 & 15.982 & \\
\hline \multirow{3}{*}{ 개인적이상자아표현 } & PSE1 & 0.905 & 13.411 & \multirow{3}{*}{0.753} \\
\hline & PSE2 & 0.895 & 13.502 & \\
\hline & PSE3 & 0.920 & 11.951 & \\
\hline \multirow{3}{*}{ 사회적이상자아표현 } & SSE1 & 1.276 & 19.281 & \multirow{3}{*}{0.908} \\
\hline & SSE2 & 1.188 & 19.266 & \\
\hline & SSE3 & 1.103 & 17.365 & \\
\hline \multirow{2}{*}{ 개인적동일시 } & PI1 & 1.086 & 16.550 & \multirow{2}{*}{0.804} \\
\hline & PI2 & 1.016 & 15.195 & \\
\hline \multirow{3}{*}{ 사회적동일시 } & SII & 1.097 & 17.323 & \multirow{3}{*}{0.865} \\
\hline & SI2 & 1.137 & 16.655 & \\
\hline & $\mathrm{SI} 3$ & 1.132 & 16.153 & \\
\hline \multirow{3}{*}{ 개인 커뮤니터몰입 } & PCCl & 0.980 & 14.369 & \multirow{3}{*}{0.841} \\
\hline & $\mathrm{PCC} 2$ & 1.200 & 17.526 & \\
\hline & $\mathrm{PCC} 3$ & 1.101 & 15.837 & \\
\hline \multirow{2}{*}{$\begin{array}{c}\text { 원천기업에 대한 긍정적 } \\
\text { 반응 }\end{array}$} & $\mathrm{CR} 1$ & 1.165 & 13.755 & \multirow{2}{*}{0.773} \\
\hline & $\mathrm{CR} 2$ & 1.194 & 15.574 & \\
\hline 모델적합도 & $x^{2}=392.51$ & 00). $G F I=0.900$, & 864. CFI & ISEA $=0.054$ \\
\hline
\end{tabular}


〈표 3〉 구성 개념간 관계 행렬

\begin{tabular}{|c|c|c|c|c|c|c|c|c|}
\hline & $\begin{array}{c}\text { 개인적 } \\
\text { 실제자아 } \\
\text { 표헌 }\end{array}$ & $\begin{array}{c}\text { 개인적 } \\
\text { 이상자아 } \\
\text { 포현 }\end{array}$ & $\begin{array}{c}\text { 사회적 } \\
\text { 실제자아 } \\
\text { 표현 }\end{array}$ & $\begin{array}{c}\text { 사회적 } \\
\text { 이상자아 } \\
\text { 포현 }\end{array}$ & $\begin{array}{l}\text { 개인적 } \\
\text { 동일시 }\end{array}$ & $\begin{array}{l}\text { 사회적 } \\
\text { 동일시 }\end{array}$ & $\begin{array}{c}\text { 개인 } \\
\text { 커뮤니티 } \\
\text { 몰입 }\end{array}$ & $\begin{array}{c}\text { 원천기업에 } \\
\text { 대한 } \\
\text { 긍정적 반응 }\end{array}$ \\
\hline $\begin{array}{c}\text { 개인적 } \\
\text { 실제자아표현 }\end{array}$ & 1.000 & & & & & & & \\
\hline $\begin{array}{c}\text { 개인적 } \\
\text { 이상자아표현 }\end{array}$ & $\begin{array}{c}0.557 \\
(0.056)\end{array}$ & 1.000 & & & & & & \\
\hline $\begin{array}{c}\text { 사회적 } \\
\text { 실제자아표헌 }\end{array}$ & $\begin{array}{c}0.630 \\
(0.047)\end{array}$ & $\begin{array}{c}0.746 \\
(0.042)\end{array}$ & 1.000 & & & & & \\
\hline $\begin{array}{c}\text { 사회적 } \\
\text { 이상자아표현 }\end{array}$ & $\begin{array}{c}0.456 \\
(0.055)\end{array}$ & $\begin{array}{c}0.631 \\
(0.048)\end{array}$ & $\begin{array}{c}0.636 \\
(0.043)\end{array}$ & 1.000 & & & & \\
\hline $\begin{array}{l}\text { 개인적 } \\
\text { 동일시 }\end{array}$ & $\begin{array}{c}0.583 \\
(0.052)\end{array}$ & $\begin{array}{c}0.685 \\
(0.049)\end{array}$ & $\begin{array}{c}0.571 \\
(0.052)\end{array}$ & $\begin{array}{c}0.538 \\
(0.051)\end{array}$ & 1.000 & & & \\
\hline $\begin{array}{l}\text { 사회적 } \\
\text { 동일시 }\end{array}$ & $\begin{array}{c}0.377 \\
(0.061)\end{array}$ & $\begin{array}{c}0.694 \\
(0.045)\end{array}$ & $\begin{array}{c}0.498 \\
(0.053)\end{array}$ & $\begin{array}{c}0.623 \\
(0.043)\end{array}$ & $\begin{array}{c}0.686 \\
(0.043)\end{array}$ & 1.000 & & \\
\hline $\begin{array}{c}\text { 개인 } \\
\text { 커뮤니티 몰입 }\end{array}$ & $\begin{array}{c}0.462 \\
(0.057)\end{array}$ & $\begin{array}{c}0.593 \\
(0.053)\end{array}$ & $\begin{array}{c}0.533 \\
(0.052)\end{array}$ & $\begin{array}{c}0.552 \\
(0.048)\end{array}$ & $\begin{array}{c}0.752 \\
(0.039)\end{array}$ & $\begin{array}{c}0.706 \\
(0.040)\end{array}$ & 1.000 & \\
\hline $\begin{array}{c}\text { 원천기업에 } \\
\text { 대한 } \\
\text { 킁정적 반응 }\end{array}$ & $\begin{array}{c}0.397 \\
(0.064)\end{array}$ & $\begin{array}{c}0.463 \\
(0.064)\end{array}$ & $\begin{array}{c}0.477 \\
(0.059)\end{array}$ & $\begin{array}{c}0.479 \\
(0.056)\end{array}$ & $\begin{array}{c}0.592 \\
(0.054)\end{array}$ & $\begin{array}{c}0.651 \\
(0.048)\end{array}$ & $\begin{array}{c}0.792 \\
(0.038)\end{array}$ & 1.000 \\
\hline
\end{tabular}

주) ( )은 표준오차

살펴본 결과 개념들간의 상관성을 의미하는 $\Phi$ matrix 계수에서 신뢰구간( $\phi \pm 2 \mathrm{~s} . \mathrm{e})$ 에 1.0 이 포함 되고 있지 않아 판별타당성을 가지고 있다고 판단하였다(Fornell and Larcker 1981).

\section{2 가설 검증}

\subsection{1 본 연구모형의 적합도 평가}

공분산 구조분석을 통해 모형의 적합도와 모 수를 추정하였으며, 검증결과 모형의 적합도 지 수는 $x^{2}=456.276(p=0.00), \mathrm{GFI}=0.883, \mathrm{AGFI}=$ 0.851, $\mathrm{CFI}=0.979, \quad \mathrm{RMSEA}=0.0608, \quad \mathrm{NFI}=$
0.962, $\mathrm{NNFI}=0.976, \mathrm{RMRS}=0.0649$ 로 나타 났다. 일반적 평가기준과 비교하여 연구 모델 이 적합도를 지니고 있다고 판단할 수 있다 (Rigdon 1998).

\section{2 .2 가설 검증 및 논의}

본 연구에서 제안한 가설의 검증 결과를 살펴 보면 첫째, 개인적 동일시에 영향을 미치는 변 수로 설정한 개인적 실제자아 표현(가설 1), 개 인적 이상자아 표현(가설 2)의 경우 모두 유의 적인 것으로 나타나 가설 $1(0.285, t=3.867)$, 가 설 $2(0.533, t=7.078)$ 는 채택되었다. 
둘째, 사회적 동일시에 영향을 미칠 것이라는 사회적 실제자아 표현(가설 3), 사회적 이상자 아 표현(가설 4)의 경우 모두 유의적으로 나타 나 가설 $3(0.228, t=3.028)$, 가설 $4(0.496, t=$ 6.439)도 모두 채택되었다.

셋째, 개인 커뮤니티 몰입에 영향을 미칠 것이라는 개인적 동일시(가설 5), 사회적 동 일시(가설 6)의 경우 유의적으로 나타나 가
설 $5(0.482, t=7.533)$, 가설 $6(0.476, t=7.683)$

은 모두 채택되었으며, 개인 커뮤니티 몰입이 원천기업에 대한 긍정적 반응에 영향을 미친다 는 가설 7 에 관한 추정치가 $0.790(t=9.444)$ 로 서 유의적으로 나타나 연구가설 7 도 채택되었다.

〈표 4〉 연구단위들간 관계 및 가설분석 결과

\begin{tabular}{|c|c|c|c|c|c|c|c|}
\hline & \multicolumn{4}{|c|}{ 가설경로 } & \multirow{2}{*}{$\begin{array}{l}\text { 표준화 } \\
\text { 추정치 }\end{array}$} & \multirow{2}{*}{$\mathrm{t}$ 값 } & \multirow{2}{*}{ 유의도 } \\
\hline & From & To & 경로명 & 부호 & & & \\
\hline $\mathrm{H1}$ & 개인적 실제자아 표현 & 개인적 동일시 & $\Upsilon_{11}$ & + & 0.285 & 3.867 & $p<.01$ \\
\hline $\mathrm{H} 2$ & 개인적 이상자아 표현 & 개인적 동일시 & $\Upsilon_{12}$ & + & 0.533 & 7.078 & $p<01$ \\
\hline H3 & 사회적 실제자아 표현 & 사회적 동일시 & $\Upsilon_{23}$ & + & 0.228 & 3.028 & $p<.01$ \\
\hline $\mathrm{H} 4$ & 사회적 이상자아 표현 & 사회적 동일시 & $\Upsilon_{24}$ & + & 0.496 & 6.439 & $p<.01$ \\
\hline H5 & 개인적동일시 & 개인 커뮤니티몰입 & $\beta_{31}$ & + & 0.482 & 7.533 & $p<.01$ \\
\hline $\mathrm{H} 6$ & 사회적동일시 & 개인 커뮤니티몰입 & $r_{32}$ & + & 0.476 & 7.683 & $p<.01$ \\
\hline $\mathrm{H} 7$ & 개인 커뮤니티몰입 & 원천기업에 대한 긍정적 반응 & $\Upsilon_{43}$ & + & 0.790 & 9.444 & $\mathrm{p}<.01$ \\
\hline
\end{tabular}

〈그림 2〉 연구모형의 경로계수

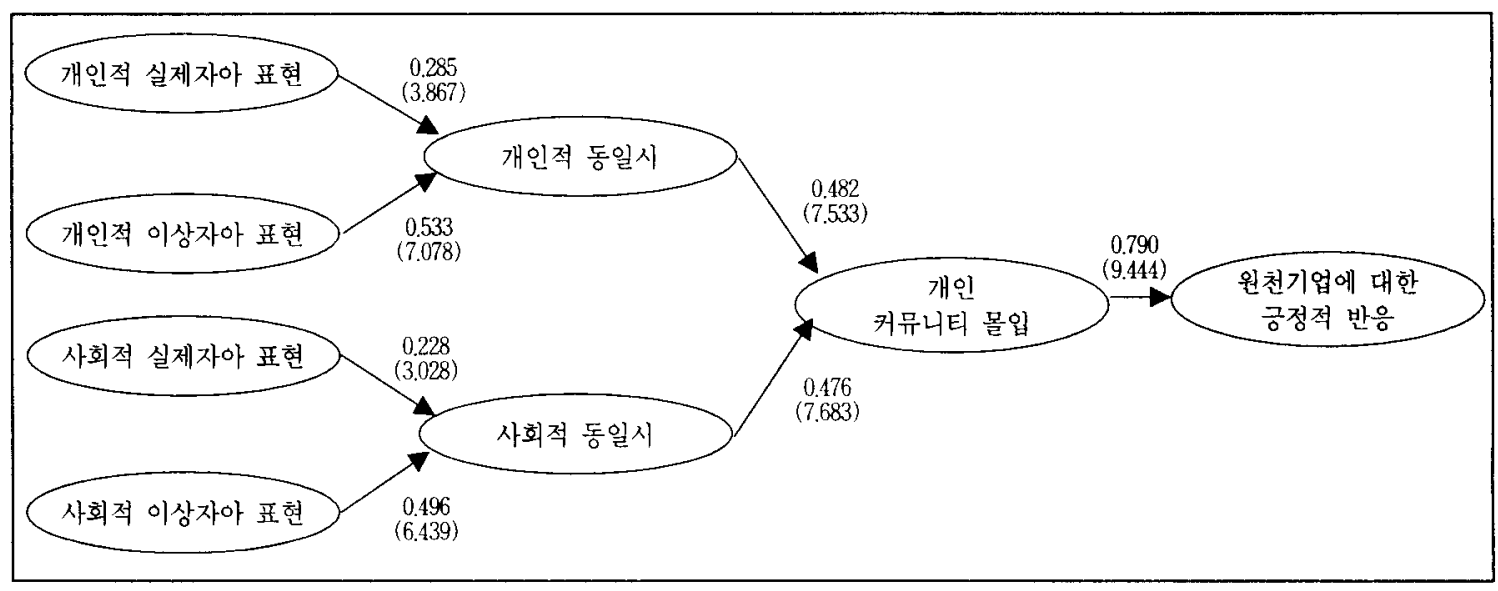

$x^{2}=456.276(p=0.00), G F I=0.883, A G F I=0.851, C F I=0.979$, RMSEA $=0.0608, N F I=0.962, N N F I=0.976, R M R S=0.0649$, ( )는 t값임 


\section{V. 결 론}

\section{1 연구 결과의 요약 및 시사점}

본 연구는 급변하는 경영 환경에 있어 중시되 고 있는 소비자들의 의견을 수렴하는 하나의 방안으로 이용되고 있는 온라인 개인 커뮤니티 의 몰입에 영향을 미치는 동일시와 자아표현을 살펴보고자 하였다. 실증 분석 결과를 요약하면 다음과 같다.

첫째, 개인적 실제자아 표현과 개인적 이상자 아 표현은 개인적 동일시에 영향을 미치고, 사 회적 실제자아 표현과 사회적 이상자아 표현은 사회적 동일시에 영향을 미치는 것을 알 수 있 었다. 즉, 온라인 개인 커뮤니티를 이용하는 소 비자들이 온라인 개인 커뮤니티에서의 개인적 존재의 입증 및 향상을 크게 느낄 경우 개인적 동일시는 높아지고, 사회적 존재의 입증 및 향 상이 클 경우 사회적 동일시는 높아진다는 것 이다. 따라서 온라인 개인 커뮤니티를 운영하는 기업은 온라인 개인 커뮤니티를 이용하는 소비 자들의 개인적 실제자아와 이상자아의 표현과 사회적 실제자아와 이상자아의 표현을 위해서 참여 정도에 따라 차별적 마케팅 활동을 전개 하고 온라인 개인 개인의 이미지를 지속적으로 관리해출 필요가 있을 것이다.

둘째, 개인적 동일시와 사회적 동일시는 모두 온라인 개인 커뮤니티 몰입에 긍정적인 영향을 미치는 것을 알 수 있다. 소비자들의 온라인 개 인 커뮤니티에 대한 몰입을 높이기 위해서는 온라인 개인 커뮤니티에 대한 개인적 동일시가 선행되어야 하고, 온라인 개인 커뮤니터를 이용
하는 구성원들과의 상호작용이 지속적으로 이 루어져야 한다는 것을 알 수 있다. 따라서 온라 인 개인 커뮤니티를 이용하는 소비자들의 동일 시 수준을 높여주기 위해서 상호작용 및 정보 제공을 용이하게 해줄 수 있는 게시판의 활성 화 및 개인의 표현력을 높여줄 수 있는 서체의 개발이나 아바타의 이용 혹은 다양한 아이템의 개발과 이용에 역점을 두어야 한다.

마지막으로 온라인 개인 커뮤니티 몰입 수준 이 높을수록 원천기업에 대한 반응은 좋게 나 타난다. 즉, 온라인 개인 커뮤니티를 이용하는 소비자들의 개인 커뮤니티 몰입 수준이 높아질 수록 다른 온라인 기업 싸이트로의 전환비용은 높아지고, 온라인 기업의 지속적 성장과 유지 존속을 위해 다른 사람에게 지속적으로 구전할 동을 할 것이며, 온라인 기업이 실시하는 이벤 트의 참여 등의 활동을 지속적으로 수행할 것 이다.

\section{2 연구의 한계 및 향후 연구 제안}

본 연구는 동일시와 자아표현이 온라인 개인 커뮤니티 몰입에 어떠한 영향을 미치는 지를 실증적으로 분석하였고, 온라인 개인 커뮤니티 몰입이 원천기업에 대한 긍정적 반응을 이끌어 내는지를 살펴보았다. 본 연구의 실증분석 결과 는 원천기업의 마케팅 관리자에게 온라인 개인 미니 홈피에 대하여 어떻게 마케팅 전략을 수 립할 것인가에 대한 시사점을 제시하는데 큰 의의가 있다. 그러나 본 연구에는 여러 가지 한 계점이 있다.

첫째, 본 연구의 한계점은 표본의 대표성에 관한 것이다. 본 연구에서는 온라인 개인 커뮤 
니티를 이용하고 있는 20대가 주요 표본이었다. 기존 커뮤니티 연구들의 경우 제한적이긴 하지 만 다양한 계층의 커뮤니티 이용자를 대상으로 하여 편중된 그들만의 문화가 아닌 다양한 문 화를 포함한 의견이 반영되도록 하였다는 점과 의 차이점을 지니고 있다. 따라서 온라인 개인 커뮤니티를 이용하는 다양한 소비자들의 의견 을 수렴하는 연구가 이루어져야만 할 것으로 판단된다.

둘째, 본 연구는 온라인 개인 커뮤니티를 이 용하는 소비자들의 자아에 $\operatorname{Sirgy}(1982,1985)$ 의 구분을 따랐으나, 자아 개념에 관한 다양한 이 론들이 존재한다는 점을 보면 동일시와 자아표 현간의 관계를 설명하는데 있어 너무 편협하게 접근이 이루어졌다는 한계를 지니고 있다. 따라 서 자아표현과 동일시의 관계를 더욱더 광범위 하게 살펴볼 필요가 있을 것이다.

셋째, 개인 커뮤니티에 몰입할 경우, 홈피를 개선하려는 노력이 유발될 수도 있다. 이에 대 한 향후 연구도 필요하다.

마지막으로 동태적 개넘인 몰입을 한 시점에 서 측정했다는 것이다. 몰입은 시간이 경과하여 소비경험이 누적되면서 형성되는 동태적 개념 이기 때문에 향후 연구에서는 시간의 흐름을 고려한 동태적인 접근법으로 몰입의 형성과정 을 실증적으로 분석한다면 보다 유용한 이론적 및 실무적 시사점을 얻을 수 있을 것이다.

〈논문 접수일: 2007. 05. 07〉

〈게재 확정일: 2007. 10. 05〉

\section{참고문헌}

김지화, 조효래(1998), "PC통신 동호회의 공동 체적 성격에 대한 일 고찰," 창원대학교 사 회과학연구, 제4호, 287-316.

박성연, 유승현(2003), “온라인 커뮤니티에서의 공동체 의식이 웹사이트 충성도와 구매의도 에 미치는 영향에 관한 연구," 경영학연구, 32(6), 1695-1713.

서문식. 김유경(2003), “온라인 브랜드 공동체 의식이 브랜드 커뮤니티 동일시와 브랜드 태도에 미치는 영향에 관한 연구," 마케팅 관리연구, 8(2), 49-77.

송창석(1997), “웹사이트 특성이 몰입에 미치는 영향에 관한 연구," 상품학연구, 제 17 호. 77-100.

송창석, 신종칠(1999), "인터넷 상호 작용성 제

고방안에 관한 연구," 마케팅연구, $14(3)$, 69-95.

신종칠(1999), "Relationship Marketing 전략의 효율화 방안에 관한 연구," 서울대학교 대 학원 박사학위 논문

안광호, 이건희(2004), "소비자-기업 동일시가 소비자의 제품 평가와 행위적 반응에 미치 는 영향에 관한 연구," 마케팅연구, 19(4), 55-77.

양석준, 박유진(2005), “개인커뮤니티 이용 동기 와 서비스 기업에 대한 원천 몰입에 관한 연구," 소비자학연구, 16(4), 129-150.

이오현(2003), "가상공간에서의 권력형성과정에 대한 사례연구," 한국언론정보학보, 23 , 79-226. 
이유재, 라선아(2002), “브랜드 퍼스낼리티-브랜 드 동일시-브랜드자산 모형: 이용자와 비이 용자간 차이에 대한 탐색적 연구," 마케팅 연구, 17(3), 1-33.

Anderson, J. C. and D. W. Gerbing(1988), "Structural Equation Modeling in Practice: A Review and Recommended Two-Step Approach," Psychology Bulletin, 103(3), 411-423.

Ashforth, B. E. and F. Meal(1989), "Social Identity Theory and Organization," Academy of Management Review, 14, 20-39.

Bergami, Massimo. and R. P. Bagozzi(2000), "Self-Categorization, Affective Commitment and Group Self-Esteem as Distinction Aspects of Social Identity in the Organization," British Journal of Social Psychology, 39(4), 555-577.

Bhattacharya, C. and Sankar Sen(2003), "ConsumerCompany Identification: A Frame-work for Understanding Consumers' Relationships with Companies," Journal of Marketing, 67(Aprill), 76-88.

Bhattacharya, C. B., H. Rao. and M. A. Glynn(1995), "Understanding the Bond of Identification: An Investigation of its Correlates among Art Museum Members," Journal of Marketing, 59(October), 46-57.

Bell. S. J. and Bulent Menguc(2002). "The Employee-Organization Relationship, Organizational Citizenship Behaviors, and $\mathrm{Su}^{-}$ perior Service Quality," Journal of Retailing, $78,131-146$.
Brewer M. B. and W. Gardner(1996), "Who is this "We"? Levels of Collective Identity and Self Representations," Journal of Personality and Social Psychology, 71, 83-93.

Dutton, Jane E., J. M. Dukerich. and C. V. Harquail(1994), "Organizational Images and Member Identification," Administrative Science Quarterly, 39(2), 239-263.

Escalas, Jennifer E. and James R. Bettman (2005). "Self-Construal, Reference Groups, and Brand Meaning," Journal of Consumer Research, 32 (December), 378-389.

Fisher, A. and C. Sonn(1999). "Aspiration to Community: Community Responses to Rejection," Journal of Community $P_{S y}-$ chology, 27(6), 715-725.

Fisher, A., and Sonn, C.(2002). "Psychological sense of community in Australia and the challenges of change," Joumal of Community Psychology , 30(6), 597-609.

Fornell, C. and D. F. Larcker(1981), "Evaluating Structural Equation Model with Unobservable Variables and Measurement Error," Joumal of Marketing Research, 18(February), 39-50.

Frank T. R. and S. Sugiyama(2001), "Virtual Internet Communities and Commercial Success: individual and community-level theory grounded in the atypical case of TimeZone.Com," Journal of Management, 27, 297-312.

Gergen, K. J.(1981), The Functions and Foibles of Negotiating Self-Conception, Advances 
in theory and research Cambridge: Ballinger. Graeff, T. R.(1996), "Using Promotional Messages to Manage the Effect of Brand SelfImage on Brand Evaluations," Journal of Consumer Marketing, 13, 4-18.

Griffin, J.(1996), "The Internet's Expanding Role in Building Customer Loyalty," Direct Marketing, Garden City, 59(7), 50-53.

Gruen T. W. J. O. Summers, and F. Acito (2000). "Relationship Marketing Activities, Commitment, and Membership Behaviors in Professional Association," Journal of Marketing, 64(July), 34-49.

Hogg, M. A.(2003), "Social identity," Handbook of Self and Identity, The Guilford Press, New York, 462 - 479.

Keller, Kevin Lane(2003), "Brand Synthesis: The Multidimensionality of Brand Knowledge," Journal of Consumer Research, 29(March), 595-600.

Kihlstrom, F., J. S. Beer. and S. B. Klein (2003), "Self and identity as memory," Handbook of Self and Identity, 68 - 90.

Kleine, Susan Schultz, Robert E. Kleine III, and Chris T. Allen(1995), "How Is a Possession 'Me' or 'Not Me'? Characterizing Types and an Antecedent of Material Possession Attachment," Journal of Consumer Research, 22 (December), 327-343.

Kozinets, Robert V.(2001), "Utopian Enterprise: Articulating the Meanings of Star Trek's Culture of Consumption," Journal of Consumer Research, Vol.28(1), 67-78.
Kumar, N., J. D. Hibbard and L. W. Stern (1994), "The Nature and Consequences of Marketing Channel Intermediary Commitment," MSI Working Paper, Report, 94-115.

Lantz, Garold and Sandra Loeb(1998), "An Examination of the Community and Purchase Preference Using the Social Identity Approach," Advances in Consumer Research, $25,486-491$.

Leary, M. and J. P. Tangney(2003), Handbook of Self and Identity, The Guilford Press, New York.

Lord R. G. and D. J. Brown(2004), "Leadership Processes and Follower Identity." Lawrence Erlbaum Associates, Mahwah. NJ.

Mael, F. B. and E. Ashforth(1992), "Alumni and Their Alma Mater: A Partial Test of The Reformulated Model of Organizational Identification," Journal of Organizational Behavior, 13, 103-123.

Markus, H. and E. Wurf(1987), "The Dynamic Self-concept: A Social Psycholigical Perspective," Annual Review of Psychology, 38, 299-337.

McAlexander, J. H., J. W. Schouten and H. F. Koening(2002), "Building Brands Community," Journal of Marketing, 66, 38-54. McMillan, D. and D. Chavis(1986). "Sense of Community: A Definition and Theory," Journal of Community Psychology, 14, 6-23. Mittal, B., B. Ratchford and P. Prabhakar 
(1990), "Functional and Expressive Attributes

as Determinants of Brand-Attitude,"

Research in Marketing. 10, 135-155.

Muniz, A. T. and T. C. O'Guinn(2001), "Brand Community," Journal of Consumer Research, 27, 412-432.

Newhagen, J. E. and S. Rafaeli(1996), "Why Communication Researchers should Study the Internet: A Dialogue," Journal of Computer Mediated Communication, 1(4).

Niedenthal, P. M. and D. R. Beike(1997), "Interrelated and Isolated Self-Concepts,"

Personality and Social Psychology Review, 1, 106-128.

Obst, P. and K. White(2005), "An Exploration of the Interplay between Psychological Sence of Community, Social Identification and Salience," Journal of Community and Applied Social Psychology, 15, 127-135.

Park, C. Whan., B. J. Jaworski. and Deborah J. MacInnis(1986). "Strategic Brand ConceptImage Management," Journal of Marketing, 50(4), 135-145.

Park, M. R. and K. Floyd(1996), "Making Friends in Cyberspace," Journal of Communication, 46, 80-97.

Richins, Marsha L.(1994), "Valuing Things: The Public and Private Meaning of Possessions," Journal of Consumer Research, 21(December), 504-521.

Ridgeway, Cecilia and J. Barkwell(1997), "Group Processes and the Diffusion of Status Beliefs," Social Psychology Quarterly, 60
(1), 14-31.

Rigdon, Edward E. (1998), "Structural Equation Modeling." In Modern Method for Business Research, G.A. Macroulides, ed. Mahwah, NJ: Lawrence Erlbaum Associates, 25194.

Rio, A. Beln del., Rodolfo Vzquez and Vctor Iglesias(2001), "The Effect of Brand Associations on Consumer Response," Journal of Consumer Marketing, 18(5), 410-425.

Rosenberg, Morris(1979) Conceiving the Self, New York: Books, Inc.

Schlenker, B. R. (1980), “Impression management: The Self-Concept, Social Identity, and Interpersonal Relations," Monterey, CA: Brooks/Cole. Seligman, C., J. M. Olson. M. P. Zanna, eds (1996), The Psychology of Values: The Ontario Sympasium, 8, Mahwah, NJ: Lawrence Erlbaum Associates, Inc.

Sedikides, C. and M. B. Brewer(2001), Individual self, relational self, collective self, Psychology Press, Philadelphia, PA.

Setterlund, Mark B. and P. M. Niedenthal (1993), "Who am I? Why am I Here? Self-Esteem, Self-Clarity, and Prototype Matching," Journal of Personality and Social Pcychology, 65, 769-780.

Sirgy, M. J.(1982), "Self-Concept in Consumer Behavior: A Critical Review," Journal of Consumer Research, 9(December), 287-300. Sirgy, M. J. (1985), "Self-Image/Product Image Congruity and Decision Making," Inter- 
national Journal of Management. 2. 49-63. Smith. S. G.. L. Zinkiewicz and C. T. Ryall (1999). "Sense of Community: Yet another Group Identification? Australian," Journal of Psychology, 51, 18.

Stole, L.(2002). "Will the real body please stand up? Boundary stories about virtual cultures," in M Benedikt(Ed.) Cyberspace: First steps. Cambridge, Massachusetts: MT Press

Swann, William B. Jr.(1990), To be Adored or to be Known? The Interplay of SelfEnhancement and Self-Verification, In Handbook of motivation and cognition: Foundations of social behavior, E, Tory Higgins, and Richard M. Sorrentino, eds, New York: Guildford, 408 - 448.

Tajfel, H. and J. C. Turner(1979), "An Integrative Theory of Social Conflict," The Social Psychology of Intergroup Relations. Monterey, CA:Brooks-Cole.
Tajfel, H. and J. C. Turner(1986), "The Social Identity Theory of Intergroup Behavior," Psychology of intergroup relations, NelsonHall, Chicago.

Triandis, H. C.(1989), "The Self and Social Behavior in Differing Cultural Contexts," Psychological Review, 96, 506-521.

Turner, J. C. and M. A. Hogg, P. J. Oakes, S. D. Reicher and M. S. Wetherell(1987), Rediscovering the Social Group: A SelfCategorization Theory, Blackwell, Oxford, UK. Valtersson, C.(1998), "Virtual communities," www.informatik.se $/ \mathrm{mlfg} / \mathrm{valter} . \mathrm{html}$

Van Knippenberg, D. and E. C. M. Van Schie (2000), "Foci and Correlates of Organizational Identification," Journal of Occupational and Organizational Psychology, 73, 137-147. Yohe, J. M.(1994), "Community Computing and The Computing Community," SIGUCCS'94, Proceedings of the 22nd ACM SIGUCCS Conference on USE Service. 


\title{
The Roles of Self-Expression and Identification on the Personal Community Commitment
}

\author{
Nak Hwan Choi* \\ Chang-Won Lee ${ }^{* *}$
}

\begin{abstract}
It can be explained by congruity theory as a process that consumers engage in a matching process to identify personal community that is congruent with their self-images to find the identification between the self and the personal community. Personal community cues that evoke certain images are viewed as activating similar beliefs about the self (e.g., high status). Individuals prompt a comparison process to determine whether the personal community and self-image are congruent and imagine prototypical users of the personal community and select ones that maximize similarity to their actual or desired self-concept.

Identity is devided into personal identity and social identity. Consumers are likely to be influenced by both personal identity and social identity.

In this article the influencing factors of the commitment to on-line personal community are explored by the sources of both personal identification and social identification.

The results are as follows. The maintenance expression and enhancement expression of personal self influence the level of personal identification positively and the maintenance expression and enhancement expression of social self influence the level of social identification positively. The level of both social and personal identification positively influence the commitment to on-line personal community which gives positive responses to the source enterprise that allows the cyberspace and the other benefits to be used.
\end{abstract}

Key words: Online Personal Community Commitment, Personal Identification, Social Identification, Expression of personal actual self, Expression of personal ideal self, Expression of social actual self, Expression of social ideal self.

* Professor. Department of Business Administration, Chonbuk National University (cnh@chonbuk.ac.kr)

** Lecturer, Department of Business Administration, Chonbuk National University 


\section{Objectives and Hypotheses}

Most individuals are aware of how they are differentiated from their surroundings. This notion is commonly referred to as an individual's sense of self. Consumers are thought to have the capacity to define themselves through their consumption episodes and the products that they purchase(Belk 1988: Escalas and Bettman 2003; Richins 1994). Consumers have the needs to express themselves through consuming the products(Mittal et al. 1990).

In the context of consumption behavior, who we are as individuals in terms of our selfesteem and our social status is related to the products that we consume. Expression of self through consuming a certain product is a part of the sense of self and can have some relationships with the identification to the products. This article aims to explore the consumer's symbolic belief that mini-homepage is the instrument to get the extrinsic advantages such as personal expression, social approval and self-esteem from the community that has created in terms of personal mini-homepage and the effects of the self-expression on the personal community commitment.

Self-concept has been treated as having two components - the actual self-concept and ideal self-concept, defined as the image of oneself that one would like to be. Sirgy(1982) has gone beyond the duality dimension and referred to actual personal self-image, ideal personal self-image, actual social self-image, and ideal social self-image. The selves direct the behaviors according to the history of environmental contingencies. Self is managed and maintained by seeking out of positive self-reinforcers and avoiding bad self-experiences. Consumers have self-verifying needs to influence other people through developing the selfverifying environments and through seeking out of the self-verifying evidences(Schlenker 1980: Swan 1990).

Personal mini-homepage is the instrument to express the self to the community created by means of mini-homepage. Her or his minihomepage consumption and precise roles that she or he wishes to enact through minihomepage should relate to consumer's sense of who she or he is. Individuals can express their selves to the community and interact with other members and fulfill the need of selfesteem in terms of self-expression via personal mini-homepage. Individuals can express to their community the evidences to maintain personal self and to enhance their prestige via their mini-homepage.

At issue is it that some of the consumercommunity relationships are based on consumer's identification with the community that helps him or her satisfy important self-definitional needs. Such identification can be volitional and selective on consumer's part. The roles of community in consumer's social identity conceptualize 
the consumer-community relationship (Ashforth, Mael 1989).

Consumer's identification with the community is based on their perception of its core characteristics. Because the personal community is created and mediated by mini-homepage, consumer-community identification relies on mini-homepage condition under which community members express their selves and interact with each other. Therefore consumers are likely to identify with the personal community that helps to satisfy their basic self-expression needs.

Consumers who engage in the online personal community construct and create their minihomepage not primarily for others to view, but also for self-realization. Consumers make efforts to construct different aspects of self and identity (Kozinets 2001). Mini-homepage users can interact with virtual space in personal and symbolic ways. Characteristics of virtual space are of the physical location embedded in a personal and symbolic forms. Mini-homepage virtual space is a space of human interaction that finds its expression in peer to peer exchange, online community. Hence self expression to the personal community through minihomepage implies becoming one's own self and being linked to the community members.

We propose that the higher the level of actual self-expression to the personal community, the higher the level of personal identification with the personal community(H1).
If self concept is personalized on the basis of personal roles in the relationship with his or her family and friends, consumers strive to verify and to enhance their personal existence (Sedikids and Brewer 2001). The level of personal identification with the community becomes higher if consumers can express their positive ideal self-images to the personal community ( $\mathrm{H} 2)$.

Social identification can be defined as a process by which individual develops ties with other person or group. The contact of the role relationship with the referent other invokes identification process(Taifel and Turner 1986).

A process of self-definition is impacted by specific membership groups and social categorization is a process which is impregnated by values, culture and social representations. Social interaction(communication and social ties) is a benefit obtained from personal community.

Personal online communities are rooted not only in real-group personal relationships, but also in members' individual interests in a specific topic. Consumers engage in consumption behavior to construct their self-concepts and to create their personal identity(Richins 1994). Associations about personal community become associated with mini-homepage the community is perceived to use.

The set of self can be linked to consumers' mental representation of self as they create mini-homepage with meanings congruent with an aspect of their current self-concept or ideal 
self-concept, thus forging an identification with the personal community.

We propose that the higher the level of actual social self-expression to the personal community, the higher the level of social identification with the personal community(H3).

In addition we propose that the higher the level of ideal social self-expression to the personal community, the higher the level of social identification with the personal community (H4).

Individuation is a never-ending process which purposes to bring the individual and collective together into unity on a higher level of self. Personal identification is based on the perception of a unique quality compared with other people' characteristics and social identification is based on the perception of a common quality shared with some other people.

Any potential identification starts with the idea that consumers may perceive themselves in terms of various levels of abstraction and will have an available subset of social categories that can become a part of their working or spontaneous self-concepts(Markus and Wurf 1987). Community identification plays an important roles as a psychological cognitive mechanism on perceiving the community(McMillan and Chavi 1986) and induces responsibility and commitment to the community by emotional connection with the other members and role performance as a member of community(Obst and White 2005).
We propose that the higher the level of personal identification with the personal community, the higher the level of commitment to the community(H5), and we propose that the higher the level of social identification with the personal community, the higher the level of commitment to the community(H6).

Consumers' positive responses to the source enterprise are defined as activities that consumers are loyal to it, resilient to negative information about it and disseminate positive word-of-mouth to other people.

Affective commitment to the personal community will induce an individual's emotional attachment and involvement with the source enterprise and is positively related to performance of the source enterprise. We propose that consumers with strong affective commitment to the personal community are willing to exert great efforts on behalf of the source enterprise (H7).

\section{Empirical Results}

\subsection{Sample}

Data were sampled from the undergraduate students of marketing class in Chonbuk National University. A total of 320 questionnaires were given, of which 299 completed were returned. The sample consisted of more women(64.5\%) 
than men $(35.5 \%)$.

\subsection{Measures and Analysis}

We analyze the data using structural equation modeling(LISREL 8.30: Jöreskog and Sörborn 1999). First, we use the entire sample to refine all the 7-point scale measures which are described in 〈Table 1〉 and test their convergent and discriminant validity (see $\langle$ Table 1〉). All internal consistency measures are greater than 0.74 , which is above the level of .70 , so the scales demonstrate internal reliability. Second, we test the hypothesized structural model ( $\langle$ Figure 1$\rangle)$. The fit indices for the model are as follows: chisquare = 456.276( $p=0.00)$, root mean square error of approximation(RMSEA) $=0.0608$, comparative fit index $(\mathrm{CFI})=0.979$. Therefore, the more robust RMSEA and CFI indices are used to assess model fit. And recent evidence suggests that CFI values of .95 or above should be used to indicate adequate overall fit(Rigdon 1998). According to these guidelines, there is evidence that our measurement model fits the data.

The results of hypotheses tests are as follows.

The paths from personal actual self-expression (H1) and personal ideal self-expression $(\mathrm{H} 2)$ to personal identification with the personal community were significantly supported.

And the paths from social actual selfexpression(H3) and social ideal self-expression (H4) to social identification with the personal community were significantly supported. The paths from personal and social identification with the personal community to personal community commitment(H5, H6) were supported.

The path from personal community Commitment to positive responses to the source enterprise(H7) also was supported.

\section{General Discussion}

This article aims to examine the effect of identification and self-expression on the online personal community, which is used as a method for the consumers to express their selves and to interact with each other.

Our experimental results are as follows.

First, we found that personal actual selfexpression and personal ideal self-expression affect the personal identification. Also actual social self-expression and ideal social selfexpression affect the social identification. That is, the more consumers feel personal existence justification and enhancement via personal community, the higher the level of personal and social identification. So the enterprise operating online personal community should encourage consumers to express their personal actual and ideal self, and to express their social actual and ideal self on the basis of not only differential marketing activities but also continuous management of online mini- 
〈Table 1) The results of factor analysis and reliability analysis on the measures

\begin{tabular}{|c|c|c|c|c|c|c|c|c|}
\hline \multirow{2}{*}{ measurement items } & \multicolumn{8}{|c|}{ Components } \\
\hline & SSS & SSE & OCC & SI & PSE & PSS & $\mathrm{PI}$ & $\mathrm{CR}$ \\
\hline $\begin{array}{l}\text { My mini-homepage helps me improve and sustain my relationships with } \\
\text { my acquaintances and friends. }\end{array}$ & .751 & .210 & .153 & .089 & .102 & .130 & .185 & .115 \\
\hline My mini-homepage helps me make new relationships with various people. & .749 & .171 & .206 & .047 & 275 & .165 & .029 & .143 \\
\hline My mini-homepage helps me easily greet my acquaintances and friends. & .743 & .253 & .056 & .002 & .180 & .165 & .051 & .035 \\
\hline $\begin{array}{l}\text { My mini-homepage helps me form and improve relations with my } \\
\text { acquaintances easily. }\end{array}$ & .729 & .116 & .113 & .267 & .140 & .216 & .103 & -.024 \\
\hline People can appreciate the style and content of my mini-homepage. & .228 & .835 & .203 & .178 & .118 & .148 & .066 & .059 \\
\hline My mini-homepage helps improve the image others have of me. & .259 & .807 & .140 & .259 & .122 & .123 & .106 & .050 \\
\hline $\begin{array}{l}\text { People can observe the positive relationships I have with acquaintances } \\
\text { and friends through my mini-homepage. }\end{array}$ & .253 & .767 & .155 & .204 & .260 & .063 & .112 & .113 \\
\hline I enjoy visiting my mini-homepage very often. & .147 & .133 & .804 & .237 & .091 & .177 & .160 & .088 \\
\hline I like my mini-homepage. & .080 & .145 & .756 & .156 & .170 & .078 & .236 & -.044 \\
\hline I think my mini-homepage is valuable. & 237 & .213 & .749 & 275 & .118 & .070 & .032 & .179 \\
\hline I identify the members of my mini-homepage community with myself. & .127 & .177 & .299 & .773 & .136 & .085 & .205 & -.012 \\
\hline $\begin{array}{l}\text { My co-workers and friends think that my miri-homepage is a good } \\
\text { on-line community. }\end{array}$ & .108 & .204 & .214 & .728 & .351 & .111 & .086 & .029 \\
\hline $\begin{array}{l}\text { My co-workers and friends have good feelings about my } \\
\text { mini-homepage service }\end{array}$ & .134 & .314 & .271 & .695 & .158 & .043 & .164 & .044 \\
\hline $\begin{array}{l}\text { It's good for me to reflect a positive image with my writings } \\
\text { through my mini-homepage. }\end{array}$ & .251 & .152 & .208 & .135 & .717 & .224 & .022 & -.015 \\
\hline $\begin{array}{l}\text { It's good for me to reflect a positive image with my onientation about } \\
\text { music through my mini-homepage. }\end{array}$ & .132 & .187 & .030 & 214 & .700 & .076 & .339 & .084 \\
\hline $\begin{array}{l}\text { It's good for me to express a positive image through my choice of mini- } \\
\text { homepage design. }\end{array}$ & .342 & .158 & .192 & .220 & .667 & .077 & .011 & .134 \\
\hline $\begin{array}{l}\text { It's good for me to reflect on my feelings or emotions through mini- } \\
\text { homepage. }\end{array}$ & .206 & .075 & .140 & .101 & .140 & .856 & .069 & .134 \\
\hline It's good for me to reflect my actual self through my home page design. & .271 & .122 & .074 & .138 & .093 & .830 & .116 & .120 \\
\hline It's good for me to post my real pictures on my mini-homepage. & .129 & .306 & .230 & -.255 & .188 & 656 & .348 & .133 \\
\hline My mini-homepage reflects my values. & .140 & .184 & .246 & .377 & .094 & .142 & .765 & .007 \\
\hline The image presented by my mini-homepage reflects my life-style. & .250 & .057 & .412 & .184 & .258 & .227 & .604 & .891 \\
\hline I enioy visiting cyworld very often. & .227 & 103 & .427 & 109 & .282 & .246 & 258 & .891 \\
\hline I will tell other people positive things about cyworld. & .193 & .146 & .158 & .028 & .108 & 248 & .098 & .843 \\
\hline Cronbach's a & 0.844 & 0.906 & 0.837 & 0.863 & 0.749 & 0.744 & 0.803 & 0.769 \\
\hline eigen value & 2.950 & 2.526 & 2.490 & 2.454 & 1.957 & 1.815 & 1.392 & 1.212 \\
\hline$\%$ of var. & 14.047 & 12.029 & 11.858 & 11.687 & 9.321 & 8,645 & 6.630 & 5.248 \\
\hline
\end{tabular}


〈Figure 1〉 Path Coefficients and Results of hypotheses tests

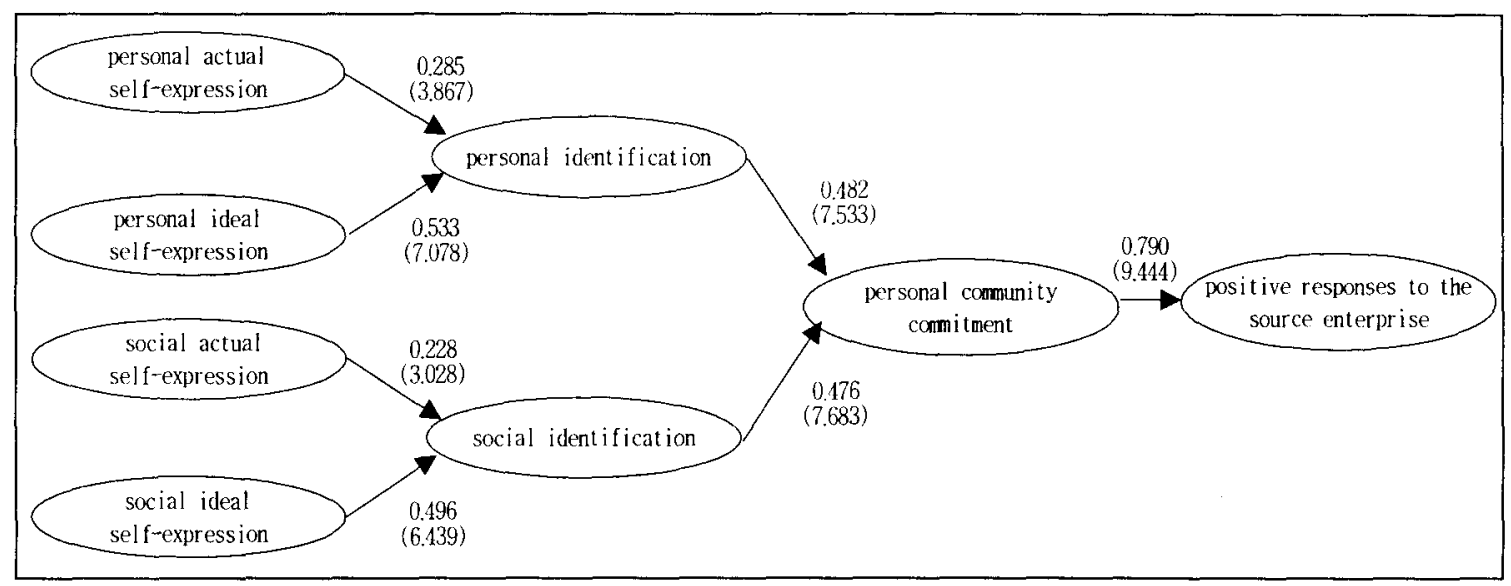

$x^{2}=456.276(\mathrm{p}=0.00), \mathrm{GFI}=0.883, \mathrm{AGFI}=0.851, \mathrm{CFI}=0.979, \mathrm{RMSEA}=0.0608, \mathrm{NFI}=0.962, \mathrm{NNFI}=0.976, \mathrm{RMRS}=0.0649$,

( ) means t-value.

homepage image.

Second, we found that both personal and social identification have positive effect on the online personal community commitment. The personal identification on online personal community and the continuous interact between members are the precedents to the strengthened consumer's commitment to online personal community. Therefore, in order to heighten the level of identification with online personal community, the enterprise should focus on the calligraphic style development. avatar application or various item development.

The last result we found is that the higher the level of online personal community commitment, the better the response to the source enterprise. That is, when the level of personal community commitment is high. the transaction cost for their transferring to other online enterprise becomes high, and they may perform word-of-mouth activities restlessly and attend the events the online enterprise offers for the continuous development and existence of the enterprise.

\section{References}

Ahn, Kwang Ho, Gun Hee Lee(2004), “The Study of the Effect of ConsumerCompany Identification on Consumer's Evaluation of Company Products and Behavioral Responses," Korean Marketing Review, 19(4), 55-77.

Anderson, J. C. and D. W. Gerbing(1988), "Structural Equation Modeling in Practice: A Review and Recommended Two-Step Approach," Psychology Bulletin, 103(3), 411-423. 
Ashforth, B. E. and F. Meal(1989), "Social Identity Theory and Organization," Academy of Management Review, 14, 20-39.

Bell, S. J. and Bulent Menguc(2002), "The Employee-Organization Relationship, Organizational Citizenship Behaviors, and Superior Service Quality," Journal of Retailing, 78, 131-146.

Bergami, Massimo, and R. P. Bagozzi(2000), "Self-Categorization, Affective Commitment and Group Self-Esteem as Distinction Aspects of Social Identity in the Organization," British Journal of Social Psychology, 39(4), 555-577.

Bhattacharya, C. and Sankar Sen(2003), "Consumer-Company Identification: A Frame-work for Understanding Consumers' Relationships with Companies," Journal of Marketing, 67(Aprill), 76-88.

Bhattacharya, C. B., H. Rao. and M. A. Glynn(1995), "Understanding the Bond of Identification: An Investigation of its Correlates among Art Museum Members," Journal of Marketing, 59(October), 46-57. Brewer M. B. and W. Gardner(1996), "Who is this "We"? Levels of Collective Identity and Self Representations," Journal of Personality and Social Psychology, 71, 83 - 93. Dutton, Jane E.. J. M. Dukerich, and C. V. Harquail(1994), "Organizational Images and Member Identification," Administrative Science Quarterly, 39(2), 239-263.

Escalas, Jennifer E. and James R. Bettman
(2005). "Self-Construal. Reference Groups, and Brand Meaning," Journal of Consumer Research, 32 (December), 378-389.

Fisher, A. and C. Sonn(1999). "Aspiration to Community: Community Responses to Rejection," Journal of Community Psychology, 27(6), 715-725.

Fisher, A., and Sonn, C. (2002). "Psychological sense of community in Australia and the challenges of change," Journal of Community Psychology , 30(6), 597-609.

Fornell, C. and D. F. Larcker(1981), "Evaluating Structural Equation Model with Unobservable Variables and Measurement Error," Journal of Marketing Research, 18 (February), 39-50.

Frank T. R. and S. Sugiyama(2001), "Virtual Internet Communities and Commercial Success: individual and community-level theory grounded in the atypical case of TimeZone.Com," Journal of Management. 27, 297-312.

Gergen, K. J.(1981). The Functions and Foibles of Negotiating Self-Conception, Advances in theory and research. Cambridge: Ballinger.

Graeff, T. R.(1996), "Using Promotional Messages to Manage the Effect of Brand SelfImage on Brand Evaluations," Journal of Consumer Marketing, 13, 4-18.

Griffin, J.(1996), "The Internet's Expanding Role in Building Customer Loyalty," Direct Marketing, Garden City, 59(7), 50-53. 
Gruen T. W., J. O. Summers, and F. Acito (2000), "Relationship Marketing Activities, Commitment, and Membership Behaviors in Professional Association," Journal of Marketing, 64(July), 34-49.

Hogg, M. A. (2003), "Social identity," Handbook of Self and Identity, The Guilford Press, New York, 462-479.

Keller, Kevin Lane(2003), "Brand Synthesis: The Multidimensionality of Brand Knowledge," Journal of Consumer Research, 29(March), 595-600.

Kihlstrom, F., J. S. Beer. and S. B. Klein (2003), "Self and identity as memory," Handbook of Self and Identity, 68 - 90.

Kim, Ji Hwa, Hyo Rae Cho(1998), "A Study on effect of PC Community Characteristic," Social Science Studies, Chang Won National University, 4, 287-316.

Kleine, Susan Schultz. Robert E. Kleine III, and Chris T. Allen(1995), "How Is a Possession 'Me' or 'Not Me'? Characterizing Types and an Antecedent of Material Possession Attachment," Journal of Consumer Research. 22 (December), 327-343.

Kozinets, Robert V.(2001), "Utopian Enterprise: Articulating the Meanings of Star Trek's Culture of Consumption," Journal of Consumer Research, Vol.28(1), 67-78.

Kumar, N.. J. D. Hibbard and L. W. Stern (1994). "The Nature and Consequences of Marketing Channel Intermediary Commitment," MSI Working Paper. Report,
94-115.

Lantz, Garold and Sandra Loeb(1998). "An Examination of the Community and Purchase Preference Using the Social Identity Approach," Advances in Consumer Research, 25, 486-491.

Leary, M. and J. P. Tangney(2003), Handbook of Self and Identity, The Guilford Press, New York.

Lee, O Hyeon(2003). "An Case-Study on the Constructing Process of Power in Cyberspace," Korea Association for Communication and Information Studies, 23, 79-226.

Lord R. G. and D. J. Brown(2004), "Leadership Processes and Follower Identity," Lawrence Erlbaum Associates, Mahwah, NJ.

Mael, F. B. and E. Ashforth(1992), "Alumni and Their Alma Mater: A Partial Test of The Reformulated Model of Organizational Identification," Journal of Organizational Behavior, 13, 103-123.

Markus, H. and E. Wurf(1987), "The Dynamic Self-concept: A Social Psycholigical Perspective," Annual Review of Psychology, 38, 299-337.

McAlexander, J. H., J. W. Schouten and H. F. Koening(2002), "Building Brands Community," Journal of Marketing, 66, 38-54.

McMillan, D. and D. Chavis(1986). "Sense of Community: A Definition and Theory," Journal of Community Psychology, 14, 6-23. Mittal, B., B. Ratchford and P. Prabhakar (1990), "Functional and Expressive Attributes 
as Determinants of Brand-Attitude," Research in Marketing, 10, 135-155.

Muniz, A. T. and T. C. O'Guinn(2001), "Brand Community," Joumal of Consumer Research, 27, 412-432.

Newhagen, J. E. and S. Rafaeli(1996), "Why Communication Researchers should Study the Internet: A Dialogue," Journal of Computer Mediated Communication. 1(4).

Niedenthal, P. M. and D. R. Beike(1997), "Interrelated and Isolated Self-Concepts," Personality and Social Psychology Review, 1, 106-128.

Obst, P. and K. White(2005), “An Exploration of the Interplay between Psychological Sence of Community, Social Identification and Salience," Journal of Community and Applied Social Psychology, 15, 127-135.

Park, C. Whan., B. J. Jaworski. and Deborah J. Macinnis(1986). "Strategic Brand ConceptImage Management," Journal of Marketing. 50(4), 135-145.

Park, M. R. and K. Floyd(1996), "Making Friends in Cyberspace," Journal of Communication, 46, 80-97.

Park, Seong Yeon, Seung Hyeon Yu(2003). "The Effect of the Sense of On-line Community on Website Loyalty and Purchase Intention," Korean Management Review, 32(6), 1695-1713.

Richins, Marsha L.(1994), "Valuing Things: The Public and Private Meaning of Possessions," Journal of Consumer Research,
21 (December), 504-521.

Ridgeway, Cecilia and J. Barkwell(1997), "Group Processes and the Diffusion of Status Beliefs," Social Psychology Quarterly, 60 (1), 14-31.

Rigdon, Edward E. (1998). "Structural Equation Modeling." In Modern Method for Business Research, G.A. Macroulides, ed. Mahwah. NJ: Lawrence Erlbaum Associates, 251-94. Rio, A. Beln del., Rodolfo Vzquez and Vctor Iglesias(2001), "The Effect of Brand Associations on Consumer Response," Journal of Consumer Marketing, 18(5), 410-425.

Rosenberg, Morris(1979) Conceiving the Self. New York: Books, Inc.

Schlenker, B. R. (1980), "Impression management: The Self-Concept, Social Identity, and Interpersonal Relations," Monterey, CA: Brooks/Cole. Seligman, C., J. M. Olson, M. P. Zanna, eds (1996), The Psychology of Values: The Ontario Symposium, 8, Mahwah. NJ: Lawrence Erlbaum Associates, Inc.

Sedikides, C. and M. B. Brewer(2001), Individual self, relational self, collective self, $\mathrm{Psy}^{-}$ chology Press, Philadelphia, PA.

Setterlund, Mark B. and P. M. Niedenthal (1993), "Who am I? Why am I Here? Self-Esteem, Self-Clarity, and Prototype Matching," Journal of Personality and Social Pcychology, 65, 769-780.

Shin, Jong Chil(1999). “A Study on the effective way to gain competitive advantage through relationship marketing: focused on market 
asset," Doctoral Dissertation, Seoul National University.

Sirgy. M. J.(1982), "Self-Concept in Consumer Behavior: A Critical Review," Journal of Consumer Research, 9(December), 287 300

Sirgy, M. J.(1985), "Self-Image/Product Image Congruity and Decision Making," International Journal of Management, 2. 49 63.

Smith, S. G., L. Zinkiewicz and C. T. Ryall (1999). "Sense of Community: Yet another Group Identification? Australian," Journal of Psychology, 51, 18.

Song, Chang Seok, Jong Chil Shin(1999), "Building Interactivity on the Internet," Korean Marketing Review, 14(3), 69-95.

Song, Chang Seok(1997), "A Study on effect of Website Characteristic on commitment," Korean Academy Of Commodity Science \& Technology, 17, 77-100.

Stole, L.(2002), "Will the real body please stand up? Boundary stories about virtual cultures," in M. Benedikt(Ed.) Cyberspace: First steps. Cambridge, Massachusetts: MIT Press

Suh, Mun Shik, Yu Kyung Kim(2003). "A Study on the Effect of Sense of Community on the Brand Community Identification and Brand Attitude in Online Brand Community," Koran Marketing Management Studies, 8(2), 49-77.

Swann, William B. Jr.(1990), To be Adored or to be Known? The Interplay of SelfEnhancement and Self-Verification, In Handbook of motivation and cognition: Foundations of social behavior, E, Tory Higgins, and Richard M. Sorrentino, eds, New York: Guildford, 408 - 448.

Tajfel, H. and J. C. Turner(1979), "An Integrative Theory of Social Conflict," The Social Psychology of Intergroup Relations. Monterey, CA:Brooks-Cole.

Tajfel, H. and J. C. Turner(1986), "The Social Identity Theory of Intergroup Behavior." Psychology of intergroup relations. NelsonHall, Chicago.

Triandis, H. C.(1989), "The Self and Social Behavior in Differing Cultural Contexts," Psychological Review, 96, 506-521.

Turner, J. C. and M. A. Hogg, P. J. Oakes, S. D. Reicher and M. S. Wetherell(1987) Rediscovering the Social Group: A SelfCategorization Theory, Blackwell, Oxford, UK.

Valtersson, C.(1998), "Virtual communities," www.informatik.se/mlfg/valter.html

Van Knippenberg, D. and E. C. M. Van Schie (2000), "Foci and Correlates of Organizational Identification," Journal of Occupational and Organizational Psychology, 73, 137-147.

Yang, Suk Joon, Yu Jin Park(2005), “A Study on the Motivation and the influence of Using Personal Community," Journal of Consumer Studies, 16(4), 129-150.

Yi, You Jae, Sun A La(2002), "Brand 
Brand Identification-Brand Equity Model: An Exploratory Study on the Difference Between Users vs. Non - Users," Korean Marketing Review. 17(3), 1-33.
Yohe, J. M.(1994), "Community Computing and The Computing Community," SIGUCCS'94, Proceedings of the 22nd ACM SIGUCCS Conference on USE Service. 